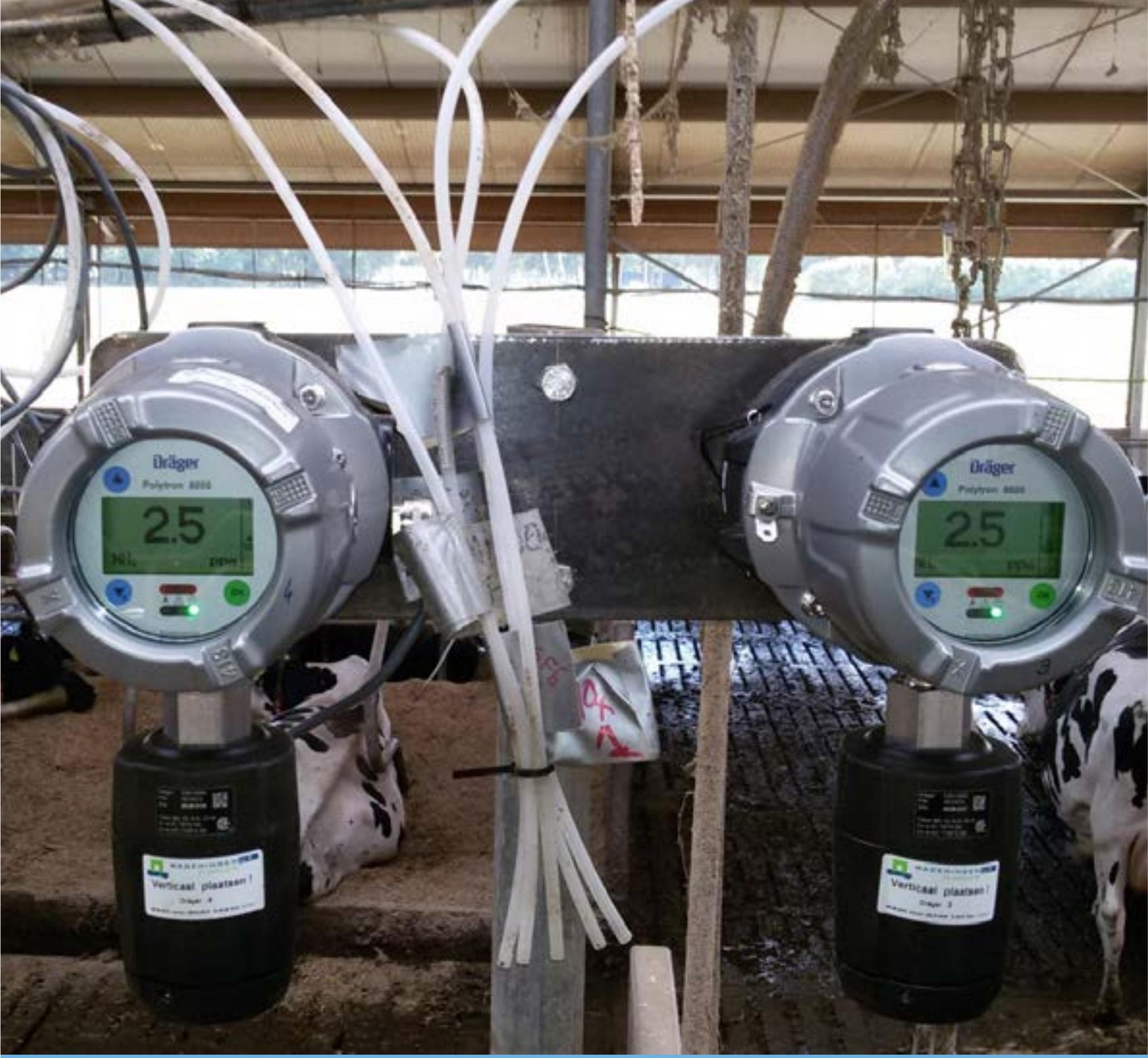

Onderzoek naar de nauwkeurigheid van een nieuw type sensor voor ammoniakconcentraties in stallucht 



\section{Onderzoek naar de nauwkeurigheid van een nieuw type sensor voor ammoniakconcentraties in stallucht}

J. Mosquera, J.P.M. Ploegaert, G.M. Nijeboer, J.M.G. Hol, R.W. Melse, N.W.M. Ogink

Dit onderzoek is uitgevoerd door Wageningen Livestock Research, in opdracht van en gefinancierd door het Ministerie van Economische Zaken, in het kader van het Beleidsondersteunend onderzoek thema's 'Stalemissies' en 'Programmatische Aanpak Stikstof' (projectnummer BO-20-004-049 / BO-20-004-093) 

Mosquera, J., J.P.M. Ploegaert, G.M. Nijeboer, J.M.G. Hol, R.W. Melse, N.W.M. Ogink, 2017. Onderzoek naar de nauwkeurigheid van een nieuw type sensor voor ammoniakconcentraties in stallucht; . Wageningen Livestock Research, Rapport 1042.

\section{Samenvatting}

In dit rapport worden de resultaten weergegeven van metingen die uitgevoerd zijn om de nauwkeurigheid van de Dräger Polytron 8000 met FL-6813260 sensor voor het meten van ammoniakconcentraties in en rondom stallen in de praktijk te onderzoeken. De sensor-resultaten zijn hiervoor vergeleken met gelijktijdige metingen uitgevoerd door de nat-chemische referentiemethode, en beoordeeld op herhaalbaarheid en juistheid (duplo-gemiddelde) t.o.v. de referentiemethode. Geconcludeerd wordt dat de Dräger sensor gelijkwaardig is aan de nat-chemische methode voor ammoniakconcentraties > $1 \mathrm{ppm}$, voor beide criteria. Voor concentraties $<1 \mathrm{ppm}$ is deze methode minder nauwkeurig in termen van juistheid, doch toepasbaar als indicatieve praktijkmethode.

\section{Summary}

This report summarizes the results of measurements performed to validate the application of the Dräger Polytron 8000 with FL-6813260 to measure ammonia concentrations from and in the vicinity of livestock housing systems. The sensor results were compared with simultaneous measurements by a reference method based on impingers with acid solution, and evaluated in terms of repeatability and trueness (duplicate means) compared to the reference method. It is concluded that the Dräger sensor is equivalent to the reference method for ammonia concentrations $>1 \mathrm{ppm}$, for both criterions. In case of concentrations $<1 \mathrm{ppm}$ the sensor Dräger sensor is not complying with the trueness criterion. However it is considered to be applicable as an indicative practical method.

Dit rapport is gratis te downloaden op http://dx.doi.org/10.18174/420967 of op www.wur.nl/livestock-research (onder Wageningen Livestock Research publicaties).

\section{(C) 2017 Wageningen Livestock Research}

Postbus 338, 6700 AH Wageningen, T 03174839 53, E info.livestockresearch@wur.nl, www.wur.nl/livestock-research. Wageningen Livestock Research is onderdeel van Wageningen University \& Research.

Wageningen Livestock Research aanvaardt geen aansprakelijkheid voor eventuele schade voortvloeiend uit het gebruik van de resultaten van dit onderzoek of de toepassing van de adviezen.

Alle rechten voorbehouden. Niets uit deze uitgave mag worden vermenigvuldigd en/of openbaar gemaakt worden door middel van druk, fotokopie, microfilm of op welke wijze dan ook zonder voorafgaande toestemming van de uitgever of auteur.

De certificering volgens ISO 9001 door DNV onderstreept ons kwaliteitsniveau. Op als onze onderzoeksopdrachten zijn de Algemene Voorwaarden van de Animal Sciences Group van toepassing. Deze zijn gedeponeerd bij de Arrondissementsrechtbank Zwolle. 


\section{Inhoud}

$\begin{array}{ll}\text { Woord vooraf } & 5\end{array}$

$\begin{array}{ll}\text { Samenvatting } & 7\end{array}$

$\begin{array}{ll}\text { Summary } & 9\end{array}$

$\begin{array}{lr}1 & 12\end{array}$

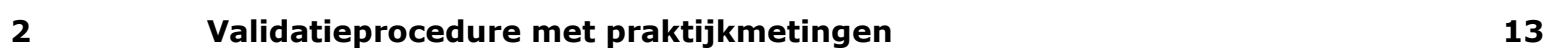

$\begin{array}{lll}2.1 & \text { Beschrijving referentiemethode (SRM) } & 14\end{array}$

2.2 Beschrijving alternatieve meetmethode (AM) 14

2.2.1 Meetprincipe $\quad 14$

2.2.2 Prestatiekenmerken 14

2.2.3 Kalibratieprocedure en bepaling responstijd 15

$\begin{array}{lll}2.3 & \text { Herhaalbaarheid van de AM } & 18\end{array}$

2.4 Juistheid van de AM 19

$\begin{array}{lll}2.5 & \text { Uitbijtertest } & 19\end{array}$

3

$\begin{array}{ll}\text { Resultaten en discussie } & \mathbf{2 1}\end{array}$

3.1 Herhaalbaarheid van de sensoren $\quad 22$

$\begin{array}{lll}3.2 & \text { Juistheid van de sensoren } & 22\end{array}$

$\begin{array}{lll}3.3 & \text { Mogelijke praktijktoepassingen } & 23\end{array}$

$\begin{array}{ll}3.3 .1 \text { Luchtwassers } & 23\end{array}$

$\begin{array}{ll}\text { 3.3.2 Melkveestallen } & 25\end{array}$

$\begin{array}{ll}3.3 .3 \text { Welzijn } & 26\end{array}$

4 Conclusies en aanbevelingen $\quad 27$

$\begin{array}{ll}\text { Literatuur } & \mathbf{2 8}\end{array}$

Bijlage 1 Certificaten kalibratiecilinders 29

Bijlage 2 Certificaten Signal 821

Bijlage 3 Certificaat EPM 797-430 39

Bijlage 4 Resultaten lab-kalibratie Dräger NH$_{3}$-sensor FL-6813260 41

$\begin{array}{lll}\text { Bijlage } 5 & \mathrm{NH}_{3} \text {-concentratiemetingen } & 42\end{array}$ 



\section{Woord vooraf}

De Duitse firma Dräger heeft een $\mathrm{NH}_{3}$-sensor ontwikkeld die volgens de specificaties van de producent toepasbaar is voor het meten van $\mathrm{NH}_{3}$-concentraties in het gebied 0,5-100 ppm. Dit instrument is in 2016 door WUR Livestock Research onder laboratorium omstandigheden in het bereik 0-11 ppm getest. De resultaten gaven aanleiding om de nauwkeurigheid van de sensor onder praktijkomstandigheden te valideren. In dit rapport worden de resultaten weergegeven van metingen die uitgevoerd zijn om de nauwkeurigheid van de Dräger Polytron 8000 met FL-6813260 sensor voor het meten van $\mathrm{NH}_{3}$-concentraties in en rondom stallen in de praktijk te onderzoeken.

Dr. Julio Mosquera, projectleider 


\section{Samenvatting}

In dit rapport worden de resultaten weergegeven van metingen die uitgevoerd zijn om de meetnauwkeurigheid van de Dräger Polytron 8000 met FL-6813260 sensor voor het meten van ammoniak $\left(\mathrm{NH}_{3}\right)$-concentraties in en rondom stallen in de praktijk vast te stellen. Voor het beoordelen van de meetnauwkeurigheid van Dräger sensor zijn de resultaten vergeleken met de nat-chemische methode, welke gehanteerd wordt als referentiemethode voor $\mathrm{NH}_{3}$-concentraties in het meetprotocol voor $\mathrm{NH}_{3}$-emissiefactoren. Voor de uitvoering en beoordeling van de resultaten is gebruik gemaakt van de CEN/TS 14793 procedure. De CEN/TS 14793 procedure is vergelijkbaar met de hiervan afgeleide procedure van RVO (2015), zij het dat in RVO (2015) soepelere criteria worden toegepast met een absoluut 95\%-betrouwbaarheidsinterval van maximaal $\pm 0,2 \mathrm{ppm}$ voor $\mathrm{NH}_{3}$-concentraties $<1 \mathrm{ppm}$, en een relatief $95 \%$-betrouwbaarheidsinterval van maximaal $\pm 20 \%$ voor $\mathrm{NH}_{3}$-concentraties $>1 \mathrm{ppm}$ als toetsingscriterium voor de herhaalbaarheid toegepast. De RVO-validatieprocedure is ontworpen om vast te stellen of onder praktijkomstandigheden een alternatieve meetmethode (AM) gelijkwaardig is aan de standaard referentiemethode (SRM) van het meetprotocol. De gelijkwaardigheid van een alternatieve methode wordt in deze procedure beoordeeld op de criteria herhaalbaarheid en juistheid. Voor beide criteria zijn in deze procedure afzonderlijke prestatie-eisen gedefinieerd voor het meetbereik $0-1 \mathrm{ppm} \mathrm{NH}$ en het meetbereik $>1 \mathrm{ppm} \mathrm{NH}_{3}$.

In de periode van 29-08-2016 tot 08-12-2016 zijn vier meetseries uitgevoerd, verdeeld over drie meetlocaties. Het betrof hier 1 melkveestal, 1 varkensstal met gecombineerd luchtwasser, en 1 vleeskalverenstal met chemisch luchtwasser. Per meetserie zijn metingen op twee meetpunten uitgevoerd (melkveestal: in de stal en buiten de stal; wasser: vóór en na de wasser). De metingen zijn per meetpunt voor zowel de AM als voor de referentiemethode SRM in duplo uitgevoerd. In totaal zijn per meetserie 4 AM-instrumenten gebruikt. De AM-instrumenten zijn gerandomiseerd toegedeeld aan de meetpunten. De AM-instrumenten draaiden continu in alle meetseries (2-3 weken per meetserie), de SRM werd alleen op een beperkt aantal dagen ( 6 of 7 dagen per meetserie) toegepast.

De resultaten van de validatiemetingen laten zien dat de Dräger Polytron 8000 met FL-6813260 sensor voor $\mathrm{NH}_{3}$ voldoet aan de eisen van de validatieprocedure voor het criterium herhaalbaarheid (instrument herhaalbaarheid) in beide meetbereiken. De gelijkwaardigheid van de Dräger sensor in termen van juistheid t.o.v. de referentiemethode (nat-chemische bepaling), is eveneens onderzocht in genoemde meetbereiken. De juistheid werd getoetst door vast te stellen of de regressielijn met het verband tussen de resultaten van beide methodes binnen de voorgeschreven bandbreedtes van de $y=x$ lijn blijft. Voor het meetbereik met $\mathrm{NH}_{3}$-concentraties > $1 \mathrm{ppm}$ voldoet de Dräger sensor aan de eisen van de validatieprocedure. Voor het meetbereik met $\mathrm{NH}_{3}$-concentraties < 1ppm voldoet dit instrument niet aan de eisen voor gelijkwaardigheid. De regressielijn ligt hier net buiten de acceptatieintervallen. Al met al kan het geconcludeerd worden dat de Dräger Polytron 8000 met FL-6813260 sensor gelijkwaardig is aan de nat-chemische methode en toegepast mag worden voor het meten van $\mathrm{NH}_{3}$-concentraties $>1 \mathrm{ppm}$. Voor concentraties $<1 \mathrm{ppm}$ is deze methode minder nauwkeurig in termen van juistheid, doch toepasbaar als indicatieve praktijkmethode.

Uit de resultaten van dit onderzoek kan worden geconcludeerd dat de Dräger Polytron 8000 met FL6813260 sensor voor $\mathrm{NH}_{3}$ een snelle responstijd heeft (minder dan 1 minuut voor $\mathrm{NH}_{3}$-concentraties > 1 ppm, minder dan 2 minuten voor $\mathrm{NH}_{3}$-concentraties $<1 \mathrm{ppm}$ ) bij veranderingen in $\mathrm{NH}_{3}-$ concentraties. Dit geldt zowel voor stijgingen in concentraties van laag naar hoog, als dalingen van hoog naar laag. Daarnaast ligt de laagste concentratie die de Dräger $\mathrm{NH}_{3}$-sensor FL-6813260 kan meten tussen 0,1-0,2 ppm. Op basis van de resultaten uit dit onderzoek wordt geadviseerd om een responstijd van 2 minuten toe te passen.

De snelle responstijd van de sensor maakt dit instrument geschikt voor metingen waar $\mathrm{NH}_{3}-$ concentraties met een hoge frequentie gemeten moeten worden. Hierbij kan gedacht worden aan het volgen van het rendement van luchtwassers (om storingen sneller te kunnen signaleren) of monitoring 
van de ammoniakconcentratie in varkens- en pluimveestallen in verband met dierenwelzijn. De gelijkwaardigheid met de referentiemethode komt tot uiting in de goede overeenstemming tussen de verwijderingsrendementen van beide methoden bij de metingen aan luchtwassers. De meetmethode is daarmee perspectiefvol als instrument voor bedrijfsmonitoring van het rendement van luchtwassers. Daarnaast biedt de meetmethode perspectief om (in combinatie met een $\mathrm{CO}_{2}$ sensor) gebruikt te worden voor het meten van de actuele ammoniakemissie van natuurlijk geventileerde rundveestallen. Hierdoor zou wellicht de mogelijkheid worden geschapen om wat betreft emissiereductie van ammoniak uit stallen een beweging te maken van middelvoorschriften naar doelvoorschriften. 


\section{Summary}

This report shows the results of measurements that were performed to determine the accuracy of the Dräger Polytron 8000 with FL-6813260 sensor for measuring ammonia (NH3) concentrations in and around animal houses in practice. To evaluate the accuracy of the Dräger sensor, the results are compared to the wet chemical method, which is used as the reference method for $\mathrm{NH} 3$ concentrations in the $\mathrm{NH3}$ emission measurement protocol. The implementation and evaluation of the results has been made using the CEN / TS 14793 procedure. The CEN / TS 14793 procedure is comparable to the RVO (2015) procedure derived from this, although in RVO (2015), more flexible criteria are applied with an absolute $95 \%$ confidence interval of up to $\pm 0.2 \mathrm{ppm}$ for $\mathrm{NH} 3$ concentrations $<1 \mathrm{ppm}$, and a $95 \%$ confidence interval of up to $\pm 20 \%$ for $\mathrm{NH} 3$ concentrations $>1 \mathrm{ppm}$ as a repeatability criterion. The RVO validation procedure is designed to determine whether, under operational conditions, an alternative measurement method (AM) is equivalent to the standard reference method (SRM) of the measurement protocol. The equivalence of an alternative method is assessed in this procedure on the criteria repeatability and accuracy. For both criteria, in this procedure separate performance requirements are defined for the measurement range $0-1 \mathrm{ppm} \mathrm{NH3}$ and the range of measurement> 1 ppm NH3.

During the period from August 29, 2016 to December 8, 2016, four measurement series were carried out, distributed over three measuring locations. It involved 1 dairy house, 1 pig house with a biological air scrubber, and 1 meat calve house with a chemical air scrubber. Per measurement series, measurements were performed at two measuring points (dairy house: in the house and outside the house; scrubber: before and after the scrubber). The measurements were performed for both the AM and the reference method SRM in duplicate per measurement point. A total of 4 AM instruments were used per measurement range. The AM instruments were randomly assigned to the measurement points. The AM instruments ran continuously in all measurement ranges (2-3 weeks per measurement range), the SRM was applied only in a limited number of days (6 or 7 days per measurement range).

The results of the validation measurements show that the Dräger Polytron 8000 with FL-6813260 sensor for $\mathrm{NH} 3$ complies with the validation procedure for the repeatability criterion (instrument repeatability) in both measuring ranges. The equivalence of the Dräger sensor in terms of accuracy with respect to the reference method (wet chemical determination) has also been investigated in these measuring ranges. The accuracy was tested by determining whether the regression line with the relationship between the results of both methods remains within the prescribed bandwidths of the $y=$ $x$ line. For the measuring range with $\mathrm{NH} 3$ concentrations $>1 \mathrm{ppm}$, the Dräger sensor meets the requirements of the validation procedure. For the measurement range with $\mathrm{NH} 3$ concentrations $<1 \mathrm{ppm}$, this instrument does not meet the requirements for equivalence. The regression line is just outside the acceptance intervals. All in all, it can be concluded that the Dräger Polytron 8000 with FL6813260 sensor is equivalent to the wet chemical method and can be used to measure $\mathrm{NH} 3$ concentrations $>1 \mathrm{ppm}$. For concentrations $<1 \mathrm{ppm}$, this method is less accurate in terms of accuracy, but applicable in practice as indicative measurement method.

From the results of this study it can be concluded that the Dräger Polytron 8000 with FL-6813260 NH3 sensor has a fast response time (less than 1 minute for $\mathrm{NH} 3$ concentrations $>1 \mathrm{ppm}$, less than 2 minutes for $\mathrm{NH} 3$ concentrations $<1 \mathrm{ppm}$ ) With changes in $\mathrm{NH} 3$ concentrations. This applies to both increases in concentrations from low to high, as well as decreases from high to low. In addition, the lowest concentration that the Dräger NH3 sensor FL-6813260 can measure lies in the range 0.1-0.2 ppm. Based on the results of this study, it is advised to apply a response time of 2 minutes.

The fast response time of the sensor makes this instrument suitable for measurements where high frequency $\mathrm{NH} 3$ concentrations should be measured. For example this could be monitoring of the efficiency of air scrubbers (in order to signal malfunctioning) or monitoring the ammonia concentration in pig and poultry farms in connection with animal welfare. The equivalence with the reference method is reflected in the correct match between the removal efficiency of both methods in the measurements of the air scrubbers. The measurement method therefore opens a perspective to be used an instrument for operational monitoring of the efficiency of air scrubbers. In addition, the measurement method provides perspective for (in combination with a $\mathrm{CO} 2$ sensor) to be used to measure the actual ammonia emission of naturally ventilated cattle houses. This might create the possibility within the regulatory framework of emission regulations from ammonia to move from prescribing defined 
abatement techniques to regulation based on emission ceiling-targets for individual farms, leaving the choice and lay-out of abatement technology to farmers 
Sinds de jaren 1990 zijn in Nederland stalmaatregelen ingevoerd om de ammoniakuitstoot uit de landbouw te verminderen. Vaststelling van het ammoniakreductiepotentieel van deze maatregelen vereist nauwkeurige metingen van de ammoniakemissie, waaruit emissiefactoren voor de betreffende maatregelen worden afgeleid die worden gebruikt in regelgeving. Emissiemetingen voor het vaststellen van emissiefactoren voor huisvestingssystemen moeten uitgevoerd worden volgens het meetprotocol voor ammoniakemissiemetingen uit huisvestingssystemen in de veehouderij (Ogink et al., 2013). In het meetprotocol is een lijst opgesteld van toegestane meetmethoden. Het meetprotocol laat toe om daarnaast alternatieve methoden te gebruiken, zolang aangetoond kan worden dat ammoniakconcentratiemetingen met de alternatieve methode (AM) gelijkwaardig zijn aan de metingen met de standaard referentiemethode (SRM) in termen van herhaalbaarheid en juistheid (RVO, 2015).

De huidige emissiereducerende stalmaatregelen zijn allen geformuleerd als zogenaamde middelvoorschriften. Dat houdt in dat de uitvoering van maatregelen nauwkeurig omschreven is in regelgeving. Door als bedrijf te voldoen aan deze omschrijving wordt verwacht dat maatregelen dezelfde emissie hebben als eerder vastgesteld in de metingen voor het vaststellen van de emissiefactor. Het nadeel van een systeem gebaseerd op doelvoorschriften is echter dat enkel technieken voorzien van een emissiefactor kunnen worden gebruikt, en dat de effectiviteit van een techniek in de praktijk vaak onvoldoende is omdat deze niet meer rechtstreeks ter plekke wordt geverifieerd. Een alternatieve aanpak is een benadering gebaseerd op een zogenaamd doelvoorschrift. Hierbij zou in vergunningverlening een maximale emissiewaarde voor het betreffende bedrijf kunnen worden vastgesteld die door middel van een bedrijfsmonitoring-systeem wordt gewaarborgd. Dit vraagt wel een betrouwbaar bedrijfsmonitoringssysteem. Om geschikt te zijn dienen monitoringsinstrumenten voldoende nauwkeurig te zijn, eenvoudig hanteerbaar en robuust in gebruik te zijn, en een aanvaardbaar prijsniveau voor een gemiddeld bedrijf te hebben. Vanwege het hoge prijsniveau komen meetmethoden die normaliter voor het meten van emissiefactoren worden gebruikt niet in aanmerking voor bedrijfsmonitoring. Geschikte betaalbare meetinstrumenten voor bedrijfsmonitoring van ammoniakemissie ontbreken tot dusver. Met name de nauwkeurigheid van in aanmerking komende sensoren in het onderste gedeelte van het voor stallen vereiste meetbereik (0.5 - 5 ppm) laat vaak te wensen over.

De Duitse firma Dräger heeft recent een $\mathrm{NH}_{3}$-sensor ontwikkeld die volgens de specificaties van de producent toepasbaar is voor het meten van $\mathrm{NH}_{3}$-concentraties in het gebied 0,5-100 ppm. Dit instrument is in 2016 door Wageningen Livestock Research onder laboratorium omstandigheden in het bereik 0-11 ppm getest (Melse et al., 2016). De conclusie uit dat onderzoek was dat de sensor een veelbelovend apparaat is voor ammoniakmetingen in en rond stallen, en geschikt om nader te evalueren onder praktijkomstandigheden met oog op de mogelijke toepassing voor bedrijfsmonitoring van ammoniakemissie uit stalgebouwen.

Het doel van dit onderzoek is de meetnauwkeurigheid van de Dräger Polytron 8000 met FL-6813260 sensor voor het meten van $\mathrm{NH}_{3}$-concentraties in en rondom stallen in de praktijk vast te stellen. Voor het beoordelen van de meetnauwkeurigheid worden in dit onderzoek de resultaten van de sensor vergeleken met de referentiemethode voor $\mathrm{NH}_{3}$-concentraties in het meetprotocol voor emissiefactoren. Daarbij wordt gebruikt gemaakt van de zogenoemde validatieprocedure van het meetprotocol (RVO, 2015). De validatieprocedure is ontworpen om vast te stellen of onder praktijkomstandigheden een alternatieve meetmethode gelijkwaardig is aan de referentiemethode van het meetprotocol. In Hoofdstuk 2 wordt de validatieprocedure beschreven. Daarnaast worden de belangrijkste kenmerken van de onderzochte sensor-meetmethode en de referentiemethode toegelicht. In Hoofdstuk 3 worden de resultaten van de metingen in de validatieprocedure weergegeven en bediscussieerd. In Hoofdstuk 4 worden de belangrijkste conclusies en aanbevelingen van deze studie samengevat. 


\section{Validatieprocedure met praktijkmetingen}

De prestatiekenmerken van de Dräger Polytron 8000 met FL-6813260 sensor zijn eerder in het lab getest (Melse e.a., 2016). Om de gelijkwaardigheid van dit meetinstrument als alternatieve methode (AM) voor het meten van $\mathrm{NH}_{3}$-concentraties aan te kunnen tonen zijn validatietests in het lab niet voldoende. De concentratiemetingen kunnen in de praktijk (binnen of in de omgeving van landbouwbronnen) worden beïnvloed door interactie met verschillende gassen en/of andere verontreinigende stoffen aanwezig in de bemonsterde lucht. Daarom is het noodzakelijk om de gelijkwaardigheid van dit instrument ook in de praktijk te valideren. Hiervoor is een validatieprocedure beschreven in RVO (2015) welke is gebaseerd op de werkwijze van de CEN/TS 14793 (2005). In deze validatieprocedure worden onder praktijkomstandigheden de meetresultaten van de AM vergeleken met de gelijktijdige verkregen meetresultaten van de standaard referentiemethode (SRM). Conform de validatieprocedure is de nat-chemische methode als SRM toegepast. De SRM wordt in hoofdstuk 2.1 beschreven, de AM in hoofdstuk 2.2. De gelijkwaardigheid van de AM en SRM is in termen van herhaalbaarheid ${ }^{1}$ en juistheid ${ }^{2}$ onderzocht.

In de periode van 29-08-2016 tot 08-12-2016 zijn vier meetseries uitgevoerd, verdeeld over drie meetlocaties. Het betrof hier 1 melkveestal ( 2 meetseries), 1 varkensstal met gecombineerd luchtwasser, en 1 vleeskalverenstal met chemisch luchtwasser, zie Tabel 1 . Per meetserie zijn metingen op twee meetpunten uitgevoerd (melkveestal: in de stal en buiten de stal; wasser: vóór en na de wasser). De metingen zijn per meetpunt voor zowel de AM als voor de referentiemethode SRM in duplo uitgevoerd. In totaal zijn per meetserie 4 AM-instrumenten gebruikt. De AM-instrumenten zijn gerandomiseerd toegedeeld aan de meetpunten (zie Tabel 1). De AM-instrumenten draaide continu in alle meetseries (2-3 weken per meetserie), de SRM werd alleen op een beperkt aantal dagen toegepast ( 7 voor meetseries $1 \mathrm{t} / \mathrm{m} \mathrm{3,6}$ voor meetserie 4; 24-uursmetingen). Tabel 1 geeft een overzicht van de meetlocaties, meetpunten, en aantal meetdagen voor de toegepaste methoden.

Tabel 1 Overzicht van meetlocaties, meetpunten, verdeling AM-sensoren over meetpunten, en aantal meetdagen voor AM- en SRM-instrumenten ( AM: alternatieve methode; SRM: referentiemethode; meetdag: 24-uursgemiddelden).

\begin{tabular}{|c|c|c|c|c|c|c|}
\hline \multirow{2}{*}{ Meetserie } & \multirow{2}{*}{ Meetlocatie } & \multirow{2}{*}{ Beschrijving } & \multirow{2}{*}{ Meetpunt } & \multirow{2}{*}{$\begin{array}{l}\text { AM- } \\
\text { nummer }\end{array}$} & \multicolumn{2}{|c|}{ Meetdagen } \\
\hline & & & & & AM & SRM \\
\hline \multirow{2}{*}{1} & \multirow{2}{*}{1} & \multirow{2}{*}{ Melkveestal (natuurlijk geventileerd) } & Binnen de stal & 3,4 & 21 & 7 \\
\hline & & & Buiten de stal & 1,2 & 21 & 7 \\
\hline \multirow{2}{*}{2} & \multirow{2}{*}{2} & \multirow{2}{*}{$\begin{array}{l}\text { Varkensstal (mechanisch geventileerd) en } \\
\text { gecombineerd luchtwasser }\end{array}$} & Drukkamer, vóór de wasser & 2,4 & 13 & 7 \\
\hline & & & Na de wasser & 1,3 & 13 & 7 \\
\hline \multirow{2}{*}{3} & \multirow{2}{*}{1} & \multirow{2}{*}{ Melkveestal (natuurlijk geventileerd) } & Binnen de stal & 1,4 & 12 & 7 \\
\hline & & & Buiten de stal & 2,3 & 12 & 7 \\
\hline \multirow{2}{*}{4} & \multirow{2}{*}{3} & Vleeskalverenstal (mechanisch & Drukkamer, vóór de wasser & 1,2 & 13 & 6 \\
\hline & & geventileerd) en chemisch luchtwasser & $\mathrm{Na}$ de wasser & 3,4 & 13 & 6 \\
\hline
\end{tabular}

\footnotetext{
${ }^{1}$ Herhaalbaarheid of precisie volgens RVO (2015): "De overeenstemming tussen onafhankelijke meetresultaten verkregen onder voorgeschreven condities. Precisie is enkel verbonden aan toevalsfouten en geeft geen informatie over systematische afwijking van de juiste waarde. De precisie van de meetmethode kan worden bepaald door de standaarddeviatie van deze metingen te berekenen"

2 Juistheid volgens RVO (2015): "De overeenstemming tussen het verwachte meetresultaat van een meting en de werkelijke meetwaarde. De meting moet een getal opleveren, dat geen systematische afwijking van de werkelijke waarde oplevert"
} 


\subsection{Beschrijving referentiemethode (SRM)}

Als referentiemethode is de nat-chemische methode met gaswasflessen gebruikt, zoals voorgesteld in RVO (2015). Deze methode is in Mosquera et al. (2017) uitgebreid toegelicht en hier wordt daarom volstaan met een korte beschrijving. Bij deze methode wordt lucht via een monsternameleiding met een constante luchtstroom aangezogen met behulp van een pomp (Thomas Industries Inc., model 607CD32, Wabasha, Minnesota ,VS) en een kritische capillair die een luchtstroom geeft van $\sim 1,0$ $\mathrm{l} / \mathrm{min}$. Alle lucht wordt door een impinger (geplaatst in een wasfles met $100 \mathrm{ml}$ 0,05 $\mathrm{M}$ salpeterzuur) geleid, waarbij de $\mathrm{NH}_{3}$ in de wasvloeistof wordt opgevangen. Om rekening te houden met eventuele doorslag worden twee extra flessen in serie geplaatst. Om doorslag naar de pomp te voorkomen wordt de lucht na de impingers met zuur door een vochtvanger (impinger zonder vloeistof) geleid. $\mathrm{Na}$ bemonstering wordt de concentratie gebonden $\mathrm{NH}_{3}$ spectrofotometrisch in de wasvloeistof bepaald. Voor en na de meting wordt de exacte luchtstroom door meetopstelling bepaald met behulp van een flowmeter (Defender 510-m, Bios Int. Corp, USA).

Door de bemonsteringsduur, de bemonsteringsflow, het $\mathrm{NH}_{4}{ }^{+}$gehalte in de vloeistof en de hoeveelheid opvangvloeistof te verrekenen kan de $\mathrm{NH}_{3}$-concentratie in de bemonsterde lucht worden bepaald. Met deze methode wordt een gemiddelde concentratie over de 24-uurs meetperiode bepaald. Dit gemiddelde resultaat geeft daardoor geen inzicht in het verloop van de $\mathrm{NH}_{3}$ concentraties tijdens de metingen.

\subsection{Beschrijving alternatieve meetmethode (AM)}

\subsubsection{Meetprincipe}

Het werkingsprincipe van het Dräger Polytron 8000 met de FL-6813260 sensor (om NH $\mathrm{N}_{3}$-concentraties in de lucht te meten) is gebaseerd op de diffusie van lucht door een membraan in de vloeibare elektrolytoplossing van de sensor. In deze elektrolytoplossing is een aantal elektroden geplaatst. In de elektrolytoplossing vindt een chemische omzetting plaats. De omvang van deze omzetting is een maatstaf voor de hoeveelheid aanwezig $\mathrm{NH}_{3}$ in het luchtmonster.

\subsubsection{Prestatiekenmerken}

De belangrijkste prestatiekenmerken volgens opgave leverancier worden in Tabel 2 en 3 samengevat.

Tabel 2 Prestatiekenmerken (opgave leverancier)

\begin{tabular}{lc} 
Parameters & Volgens leverancier \\
Detectiegrens $(\mathrm{ppm})$ & 1 \\
\hline Maximale meetbereik $(\mathrm{ppm})$ & 100 \\
\hline Kalibratie & 2 -punten kalibratie $\left(\mathrm{NH}_{3}\right.$ en nulgas) \\
\hline Meetonzekerheid & $< \pm 5 \%$ van gemeten waarden, met een ondergrens van 1,5 ppm \\
\hline Bedrijfstemperatuur en -luchtvochtigheid & $-40 / 65^{\circ} \mathrm{C}$ en $15 / 95 \%$ \\
\hline Luchtdruk & Omgevingsdruk (1 bar) \\
\hline Kruisgevoeligheid & Zie Tabel 3
\end{tabular}




\begin{tabular}{|c|c|c|}
\hline Gas & Concentratie (ppm) & $\mathrm{NH}_{3}$-sensor $(\mathrm{ppm})$ \\
\hline $\mathrm{CO}$ & 100 & $<0,5$ \\
\hline $\mathrm{H}_{2} \mathrm{~S}$ & 20 & $<0,8$ \\
\hline $\mathrm{NO}_{2}$ & 10 & $<0,7$ \\
\hline NO & 20 & $<0,5$ \\
\hline $\mathrm{CO}_{2}$ & 16.000 & $<0,5$ \\
\hline $\mathrm{H}_{2}$ & 1.000 & $<0,5$ \\
\hline $\mathrm{Cl}_{2}$ & 10 & -6 \\
\hline $\mathrm{C}_{2} \mathrm{H}_{4}$ & 1.000 & $<0,5$ \\
\hline $\mathrm{HCN}$ & 50 & $<0,5$ \\
\hline $\mathrm{C}_{2} \mathrm{H}_{5} \mathrm{OH}$ & 250 & $<0,5$ \\
\hline $\mathrm{H}_{2} \mathrm{O}_{2}$ & 10 & $<0,5$ \\
\hline Limonene $^{a}$ & Saturated & $<0,5$ \\
\hline Peracetic acid & Saturated & $<0,5$ \\
\hline $\mathrm{N}_{2} \mathrm{O}$ & 10.000 & $<0,5$ \\
\hline
\end{tabular}

a 1-Methyl-4-(1-methylethenyl)-cyclohexene; ${ }^{\mathrm{b}} \mathrm{CH}_{3} \mathrm{CO}_{3} \mathrm{H}$.

Melse et al. (2016) hebben de prestatiekenmerken van dit instrument in het lab getest en kwamen tot de volgende conclusies:

- Wanneer twee Dräger Polytron 8000-apparaten met FL-6813260 sensor werden blootgesteld aan dezelfde lucht, werden vergelijkbare concentraties met beide apparaten gemeten (voor concentraties hoger dan $1 \mathrm{ppm}$ ).

- $\quad \mathrm{Er}$ is een klein effect van relatieve luchtvochtigheid op de $\mathrm{NH}_{3}$-concentraties die gemeten worden met de sensoren.

- De kalibratie is niet lineair in het concentratiegebied 0-11 ppm. Daarom is aanbevolen om aparte kalibraties te maken voor de lage concentraties (0-1 ppm) en de hoge concentraties (1-11 ppm).

- De meetonzekerheid (0,11 ppm voor concentraties lager dan $1 \mathrm{ppm} ; 3 \%$ voor concentraties hoger dan $1 \mathrm{ppm}$ ) was lager dan wat de leverancier had opgegeven.

\subsubsection{Kalibratieprocedure en bepaling responstijd}

De vier ingezette sensoren werden vóór en na elke meetserie gekalibreerd. De sensoren zijn in het laboratorium tegen standaard $\mathrm{NH}_{3}$-kalibratiegassen $\left(9,9\right.$ ppm in $\mathrm{N}_{2}, 11,0$ ppm in $\mathrm{N}_{2}$ en 101,0 ppm in $\mathrm{N}_{2}$, Scott Specialty Gases; zie certificaten in Bijlage 1) gekalibreerd volgens het schema opgenomen in Tabel 4. De kalibraties vonden plaats bij een kamertemperatuur van $20-23{ }^{\circ} \mathrm{C}$ en een druk van $1015-$ $1022 \mathrm{hPa}$. De kalibratie omvatte de volgende stappen:

A. Eerst werden de sensoren in verticale positie vastgezet, en werd een doorzichtige meetkamer onder de sensoren geplaatst (Figuur 1). De meetkamer is geplaatst om ervoor te zorgen dat de concentratie in de lucht die de sensoren bereikt stabiel is, en om te bewerkstelligen dat de lucht passief de sensoren kan bereiken. Vervolgens werd gedurende minimaal 8 uur schone perslucht (flow: ca. $3 \mathrm{l} / \mathrm{min}$ ) aangeboden voordat de kalibratiegassen werden aangeboden.

B. Gas van de gascilinders met kalibratiegas werd met behulp van twee verdunningsapparaten met persdruk verdund. Met één van de verdunningsapparaten (Signal Model 821; Figuur 2) kunnen verschillende verdunningsstappen (van $0 \%$ tot $100 \%$, in stappen van $10 \%$ ) worden gemaakt (zie Bijlage 2). Voor lage concentraties ( $<1 \mathrm{ppm}$ ) is een tweede verdunningsapparaat (EPM Diluting Stack Sampler, type 797-430; Figuur 2) in serie na het eerste verdunningsapparaat geplaatst. Deze werd alleen met een vast (gekalibreerde) verdunningsratio van 1 : 10 (6.0 bar) gebruikt (zie Bijlage 3). In Bijlage 2 en 3 zijn de kalibratiecertificaten van beide verdunningsapparaten weergegeven. 
C. Het verdunde gas werd daarna naar de meetkamer geleid (met voor elke sensor een eigen meetkamer), waar de $\mathrm{NH}_{3}$ sensoren zijn geplaatst (Figuur 1). Om te controleren of de gasverdeling naar de sensoren gelijkmatig was, werd na het aanbieden van een bepaalde $\mathrm{NH}_{3}$-concentratie gekeken of de reactietijd van de sensoren vergelijkbaar was. Per kalibratiestap (zie tabel 4) is gedurende minimaal 20 minuten gemeten (15 minuten voor hoge concentraties $(>1 \mathrm{ppm})$ ). Tussen het meten van hoge $(>1 \mathrm{ppm})$ en lage $(<1 \mathrm{ppm})$ concentraties werden de leidingen (FEP) met schone perslucht gespoeld.

D. Met behulp van een precisieweerstand van $50 \Omega$ (Neohm UPW-50, $\pm 0,1 \%, 3 \times 10-6 \Omega /{ }^{\circ} \mathrm{C}$ ) is het 4 - $20 \mathrm{~mA}$ uitgangssignaal van de sensoren omgebouwd tot een $200-1000 \mathrm{mV}$ signaal, dat elke 10 seconden geregistreerd werd met een datalogger (Campbell Scientific Inc., Logan UT, USA; het type CR1000). De resolutie van de datalogger is $0,1 \mathrm{mV}$ (d.w.z. 0,0125 ppm) voor waarden tussen 200 en $800 \mathrm{mV}$ (0-75 ppm), en $1 \mathrm{mV}$ (d.w.z. 0,125 ppm) voor waarden boven $800 \mathrm{mV}$ (> $75 \mathrm{ppm}$ ). Deze waarden zijn omgezet naar ppm door aan te nemen dat 4 $\mathrm{mA}$ gelijk is aan $0 \mathrm{ppm}$, en $20 \mathrm{~mA}$ aan $100 \mathrm{ppm}$, volgens de specificaties van de sensor (zie Tabel 5).

De responstijd van de sensoren werd vastgesteld door de tijd te bepalen die nodig is om vanaf het moment van aanbieding van een concentratie $90 \%$ van de aangeboden concentratie te bereiken. In Bijlage 4 wordt, per meetserie en sensor, de toegepaste kalibratielijn in tabelvorm gepresenteerd.
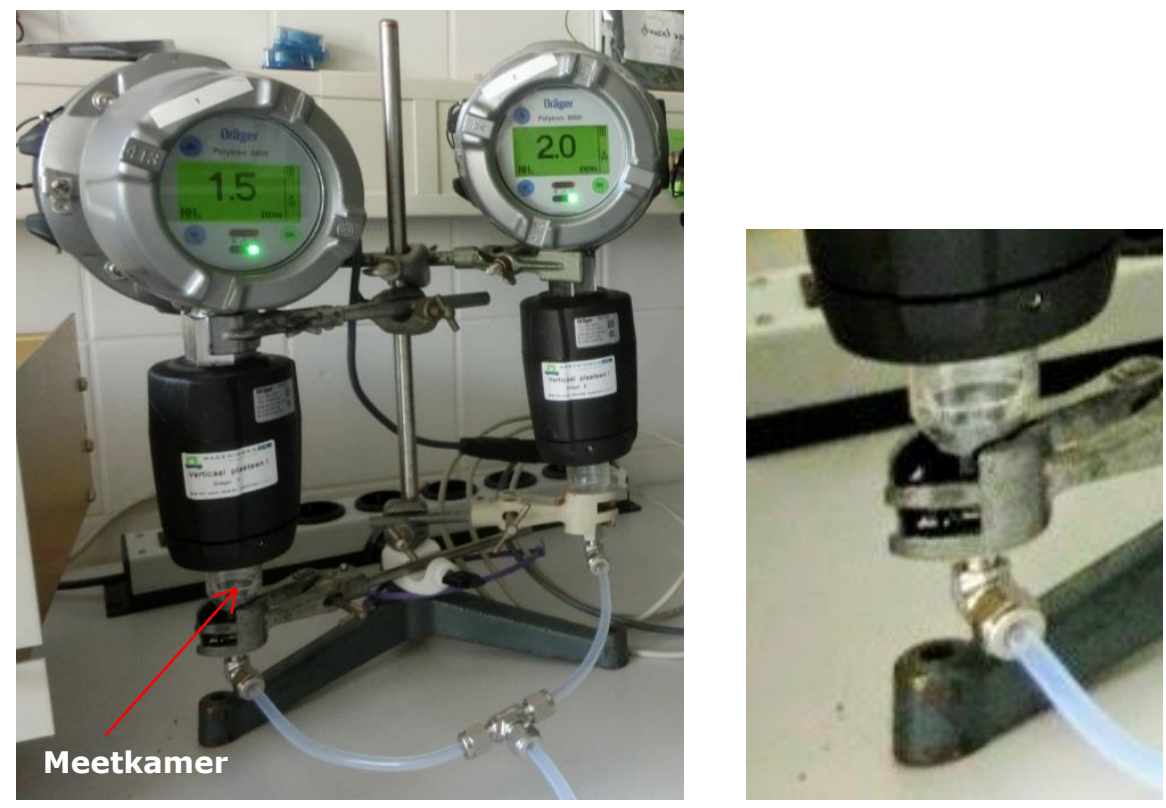

Figuur 1 Twee Dräger $\mathrm{NH}_{3}$-sensor FL-6813260 met meetkamers zoals gebruikt tijdens kalibratie in het lab.
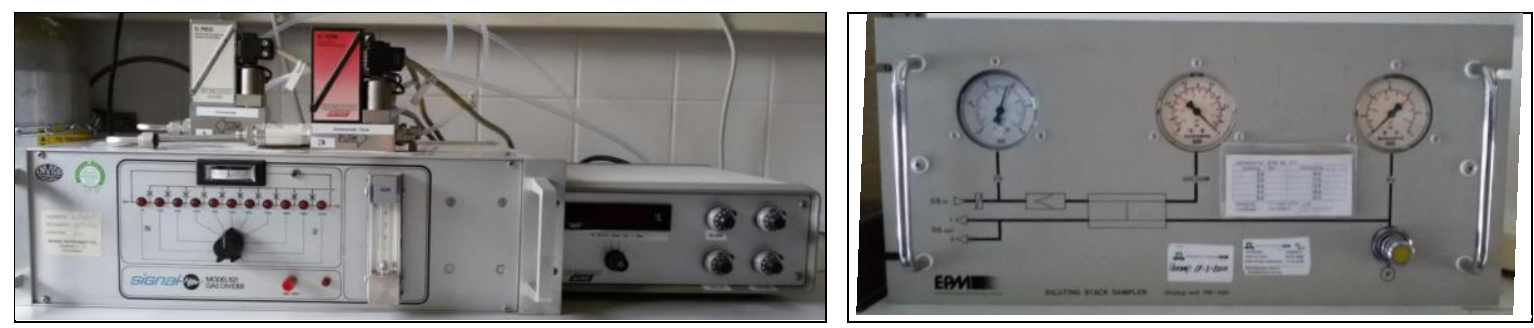

Figuur 2 Links: Signal Model 821; Rechts: EPM Diluting Stack Sampler, type 797-430 
Tabel 4 Verdunningsstappen voor de kalibratie van de Dräger $\mathrm{NH}_{3}$-sensor FL-6813260.

$\mathrm{NH}_{3}$-cilinder ( $\left.\mathrm{ppm}\right)$ Perslucht

9,9
9,9
9,9

$9,9 \quad 50$

9,90

9,9

9,90

9,90

9,9

9,9

$9,9 \quad 20$

9,9

$9,9 \quad 40$

9,950

9,9

9,9

$9,9 \quad 80$

9,9

$9,9 \quad 100$

$11 \quad 10$

1120

$11 \quad 30$

$11 \quad 40$

$11 \quad 50$

$11 \quad 60$

1170

$11 \quad 80$

1190

11

$\begin{array}{ll}11 & 20 \\ 11 & 30 \\ 11 & 50\end{array}$

$\begin{array}{lll}11 & 50 & 10 \\ 101 & 10 \\ 101 & 20\end{array}$

$\begin{array}{ll}101 & 30 \\ 101 & 40 \\ 101 & 50\end{array}$

$\begin{array}{ll}101 & 50 \\ 101 & 10\end{array}$

$101 \quad 20$

$\begin{array}{lll}101 & 30 & 10 \\ 101 & 40\end{array}$

$\begin{array}{lll}101 & 40 & 10 \\ 101 & 50 & 10 \\ 101 & 60\end{array}$

$\begin{array}{ll}101 & 60 \\ 101 & 70\end{array}$

$101 \quad 80$

101

90

90

$---$

1,00

1,98

$\begin{array}{ll}--- & 2,97\end{array}$

--- $\quad 3,95$

--- 4,95

--- $\quad 5,93$

--- $\quad 6,91$

--- $\quad 7,90$

--- $\quad 8,90$

---
-

$10 \quad 0,10$

$10 \quad 0,20$

$10 \quad 0,30$

$10 \quad 0,39$

$10 \quad 0,50$

$10 \quad 0,59$

$10 \quad 0,70$

$10 \quad 0,79$

$10 \quad 0,89$

$10 \quad 0,99$

--- 1,11

$\begin{array}{ll}--- & 2,20\end{array}$

$\begin{array}{ll}-- & 3,30\end{array}$

$\begin{array}{ll}-- & 4,38\end{array}$

--- $\quad 5,50$

$\begin{array}{ll}-- & 6,58\end{array}$

$\begin{array}{ll}-- & 7,68\end{array}$

--- $\quad 8,78$

$\begin{array}{ll}--- & 9,89\end{array}$

$---11,00$

$10 \quad 0,11$

$10 \quad 0,22$

$10 \quad 0,33$

$10 \quad 0,55$

--- 10,17

-- $\quad 20,20$

--- 30,31

$---40,25$

--- $\quad 50,53$

$10 \quad 1,02$

$10 \quad 2,02$

$10 \quad 3,03$

$10 \quad 4,02$

$10 \quad 5,05$

$10 \quad 6,04$

$10 \quad 7,05$

10
10
10,06


Tabel 5 Regressielijn voor het omzetten van het uitgangssignaal (in $\mathrm{mV}$ ) van de Dräger $\mathrm{NH}_{3}$ sensor FL-6813260 naar $\mathrm{NH}_{3}$-concentraties in ppm conform specificaties producent(*).

\begin{tabular}{|c|c|c|c|c|}
\hline Sensor & $\begin{array}{c}\text { Serienummer } \\
\text { sensor }\end{array}$ & Weerstand & $\begin{array}{c}\text { NH3 (ppm) } \\
\text { a }\end{array}$ & $\begin{array}{l}\text { signaal + b } \\
\text { b }\end{array}$ \\
\hline 1 & ARJE-0001 & 49.97 & 1.2508 & -25.0 \\
\hline 2 & ARJC-0004 & 49.98 & 1.2505 & -25.0 \\
\hline 4 & ARJC-0011 & 49.96 & 1.2510 & -25.0 \\
\hline
\end{tabular}

$(*)$ Alle vier de sensoren hebben EEPROM versie 3 en software versie 2.07 (op het display wordt het laatste cijfer van de software versie niet getoond en is "2.0" zichtbaar).

\subsection{Herhaalbaarheid van de AM}

De herhaalbaarheid van de AM in de praktijk is getest door de procedure te volgen zoals beschreven in CEN/TS 14793 (2005). Voor alle metingen zijn bij elk meetpunt twee AM-instrumenten geplaatst om tegelijkertijd de $\mathrm{NH}_{3}$-concentratie bij gelijke omstandigheden te meten. Daarna zijn de volgende stappen uitgevoerd om de herhaalbaarheid van de AM te valideren:

1. Voor alle bruikbare metingen (en zonder uitbijters, zie hoofdstuk 2.5$)(i=1 \ldots n)$ is de gemiddelde concentratie $\left(Y_{i}\right)$ bepaald:

$$
Y_{i}=\frac{\left(Y_{i 1}+Y_{i 2}\right)}{2}
$$

2. Voor de metingen waar de gemiddelde concentratie $Y_{i}<1$ ppm, is het tweezijdig 95\%betrouwbaarheidsinterval van de metingen op absoluut niveau $\left(C L_{95 \%}^{a}\right)$ bepaald door:

a. Het aantal metingen ( $n_{\text {laag }}$ ) met een gemiddelde concentratie $Y_{i}<1$ ppm te selecteren.

b. Voor deze nlaag-metingen, het verschil in concentratie $\left(D_{i}\right)$ tussen beide instrumenten en de absolute standaarddeviatie $\left(\mathrm{S}_{\mathrm{a}}\right)$ van de metingen te bepalen volgens de vergelijkingen:

$$
D_{i}=\left(Y_{i 1}-Y_{i 2}\right) ; \quad S_{a}=\sqrt{\frac{\sum_{i=1}^{n \text { laag }} D_{i}^{2}}{2 * n_{\text {laag }}}}
$$

c. De kritische $t$-waarde $\left(t_{f ; 95 \%}\right)$ voor een tweezijdige t-toets met $f=n_{\text {laag }}-2$ vrijheidsgraden en een 95\%-betrouwbaarheidswaarde te bepalen.

d. Het tweezijdig $95 \%$-betrouwbaarheidsinterval op absoluut niveau ( $C L_{95 \%}^{a}$ ) wordt bepaald als:

$$
C L_{95 \%}^{a}=S_{a} * t_{f ; 95 \%}
$$

3. Voor de metingen waar de gemiddelde concentratie $Y_{i}>1 \mathrm{ppm}$, is het tweezijdig $95 \%$ betrouwbaarheidsinterval van de metingen op relatief niveau $\left(C L_{95 \%}^{r}\right)$ bepaald door:

a. Het aantal metingen ( $n_{\text {hoog }}$ ) met een gemiddelde concentratie $Y_{i}>1$ ppm te selecteren.

b. Voor deze nhoog-metingen, het verschil in concentratie $\left(D_{i}\right)$ tussen beide instrumenten en de relatieve standaarddeviatie $\left(\mathrm{S}_{r}\right)$ van de metingen te bepalen:

$$
D_{i}=\left(Y_{i 1}-Y_{i 2}\right) ; \quad S_{r}=\sqrt{\frac{\sum_{i=1}^{\text {nhoog }}\left(D_{i} / Y_{i}\right)^{2}}{2 * n_{\text {hoog }}}}
$$

c. De kritische $t$-waarde $\left(t_{f} ; 95 \%\right)$ voor een tweezijdige $t$-toets met $f=n_{\text {hoog }}-2$ vrijheidsgraden en een $95 \%$-betrouwbaarheidswaarde te bepalen.

d. Het tweezijdig 95\%-betrouwbaarheidsinterval op relatief niveau ( $\left.C L_{95 \%}^{r}\right)$ wordt bepaald als:

$$
C L_{95 \%}^{a}=S_{a} * t_{f ; 95 \%}
$$

\section{De criteria voor acceptatie van de AM in termen van herhaalbaarheid zijn:}

1. Voor een gemiddelde concentratie $Y_{i}<1$ ppm: het betrouwbaarheidsinterval (zoals hierboven beschreven) moet kleiner zijn dan 0,1 ppm.

2. Voor een gemiddelde concentratie $Y_{i}>1 \mathrm{ppm}$ : het betrouwbaarheidsinterval (zoals hierboven beschreven) moet kleiner zijn dan 0,1 (10\%). 
De CEN/TS 14793 procedure is vergelijkbaar met de hiervan afgeleide procedure van RVO (2015), zij het dat in RVO (2015) soepelere criteria worden toegepast met een absoluut 95\%-

betrouwbaarheidsinterval van maximaal $\pm 0,2 \mathrm{ppm}$ voor $\mathrm{NH}_{3}$-concentraties $<1 \mathrm{ppm}$, en een relatief $95 \%$-betrouwbaarheidsinterval van maximaal $\pm 20 \%$ voor $\mathrm{NH}_{3}$-concentraties $>1 \mathrm{ppm}$ als toetsingscriterium voor de herhaalbaarheid toegepast. In dit rapport worden de strengere eisen van CEN/TS 14793 (2005) aangehouden.

\section{$2.4 \quad$ Juistheid van de AM}

De gelijkwaardigheid van de AM en SRM in termen van juistheid is in de praktijk getest door de procedure te volgen zoals beschreven in CEN/TS 14793 (2005). Deze procedure is vergelijkbaar met RVO (2015). Voor alle metingen zijn bij elke meetpunt zowel voor de AM als voor de SRM twee instrumenten (metingen in duplo) geplaatst om tegelijkertijd de $\mathrm{NH}_{3}$-concentratie bij gelijke omstandigheden met beide methoden te meten. De nulhypothese in deze test is dat de duplogemiddelde concentraties die gemeten zijn met beide methoden (AM en SRM) gelijk zijn (voor alle bruikbare metingen, en zonder uitbijters, zie hoofdstuk 2.5), met als gevolg dat een lineaire regressie $(A M=a+b * S R M)$ een regressiecoëfficiënt $b=1$ (helling) en een afsnijpunt $a=0$ oplevert. Om deze hypothese te valideren zijn de volgende stappen uitgevoerd:

1. Voor de lineaire regressie $\left(y=a+b^{*} x\right)$ van de concentraties met de $A M\left(Y_{i j}\right)$ en de SRM $\left(X_{i j}\right)$, zijn de volgende parameters bepaald:
a. Afsnijpunt
b. Helling
c. Determinatiecoëfficiënt $\left(R^{2}\right)$

2. De tweezijdig acceptatie-intervallen voor toetsing van juistheid zijn bepaald volgens:

a. $y=(x \pm 0,1)$ ppm voor gemiddelde SRM concentraties $<1 \mathrm{ppm}$

b. $y=0,9 * x$ ppm en $y=1,1 * x$ ppm voor gemiddelde SRM concentraties $>1 \mathrm{ppm}$

3. Tenslotte is een grafiek gemaakt met:

a. Per meting, de gemiddelde waarde $\left(y_{i}\right)$ van de beide AM-instrumenten, en de gemiddelde waarde $\left(x_{i}\right)$ van de duplo-SRM (i.e. de waarden $\left(x_{i}, y_{i}\right)$ )

b. De lijn die de nulhypothese vertegenwoordig $(y=x)$

c. De geschatte lineaire regressielijn $(y=a+b * x)$

d. De tweezijdig acceptatie-intervallen zoals gedefinieerd bij 1 en 2 .

\section{De criteria voor acceptatie van de AM in termen van gelijkwaardigheid (juistheid) zijn:}

1. $R^{2} \geq 0,95$.

2. De geschatte lineaire regressielijn treedt niet buiten de grenzen van de acceptatie-intervallen

\subsection{Uitbijtertest}

De data werd gecontroleerd op de aanwezigheid van uitbijters door middel van de boxplot-methode met driemaal de IKA-waarde (interkwartiel-afstand) als maat voor uitbijter. De volgende procedure werd toegepast:

1. Per meting $(i=1,2, . ., 54)$ is gekeken naar de verhouding tussen het verschil in concentratiewaarde en de gemiddelde waarde bij de AM en de SRM:

$$
\text { verhouding }_{i}=\frac{\left|C_{i}(A M)-C_{i}(S R M)\right|}{\left(C_{i}(A M)+C_{i}(S R M)\right) / 2}
$$

2. Met deze verhouding-getallen is een database gemaakt en de volgende parameters bepaald:

a. het eerste kwartiel (Q1): ten minste $1 / 4$ van de data is niet groter dan Q1, en ten minste 3/4 van de data is niet kleiner dan Q1

b. het derde kwartiel (Q3): ten minste 3/4 van de data is niet groter dan Q3, en ten minste 1/4 van de data is niet kleiner dan Q3

c. het interkwartiel-afstand (IKA): IKA = Q3-Q1 
d. ondergrens voor uitbijter: Uit_onder $=$ Q1-3*IKA

e. bovengrens voor uitbijter: Uit_boven $=Q 3+3 *$ IKA

3. Waarden in een meetserie worden als uitbijter beschouwd wanneer:

a. verhouding $<$ Uit_onder of

b. verhouding $>$ Uit_boven 


\section{Resultaten en discussie}

Uit de labmetingen blijkt dat de Dräger $\mathrm{NH}_{3}$-sensor $\mathrm{FL}-6813260$ snel reageert op veranderingen in de aangeboden NH3-concentraties, zowel van lage naar hoge concentraties (Figuur 3a) als van hoge naar lage concentraties (Figuur 3b). De responstijd van de sensor is lager dan 1 minuut voor $\mathrm{NH}_{3}-$ concentraties $>1$ ppm maar loopt op bij lagere concentraties. Voor $\mathrm{NH}_{3}$-concentraties $<1 \mathrm{ppm}$ wordt daarom op basis van deze resultaten geadviseerd om minimaal 2 minuten responstijd te gebruiken (Figuur 3c). De labmetingen laten ook geen significant verschil in het outputsignaal van de apparaten zien wanneer concentraties van 0 en 0,1 ppm worden aangeboden. Wanneer een concentratie van 0,2 ppm wordt aangeboden is het outputsignaal van de apparaten wel significant groter. Geconcludeerd kan worden dat de laagste concentratie die de Dräger $\mathrm{NH}_{3}$-sensor FL-6813260 kan meten tussen 0,10,2 ppm ligt.
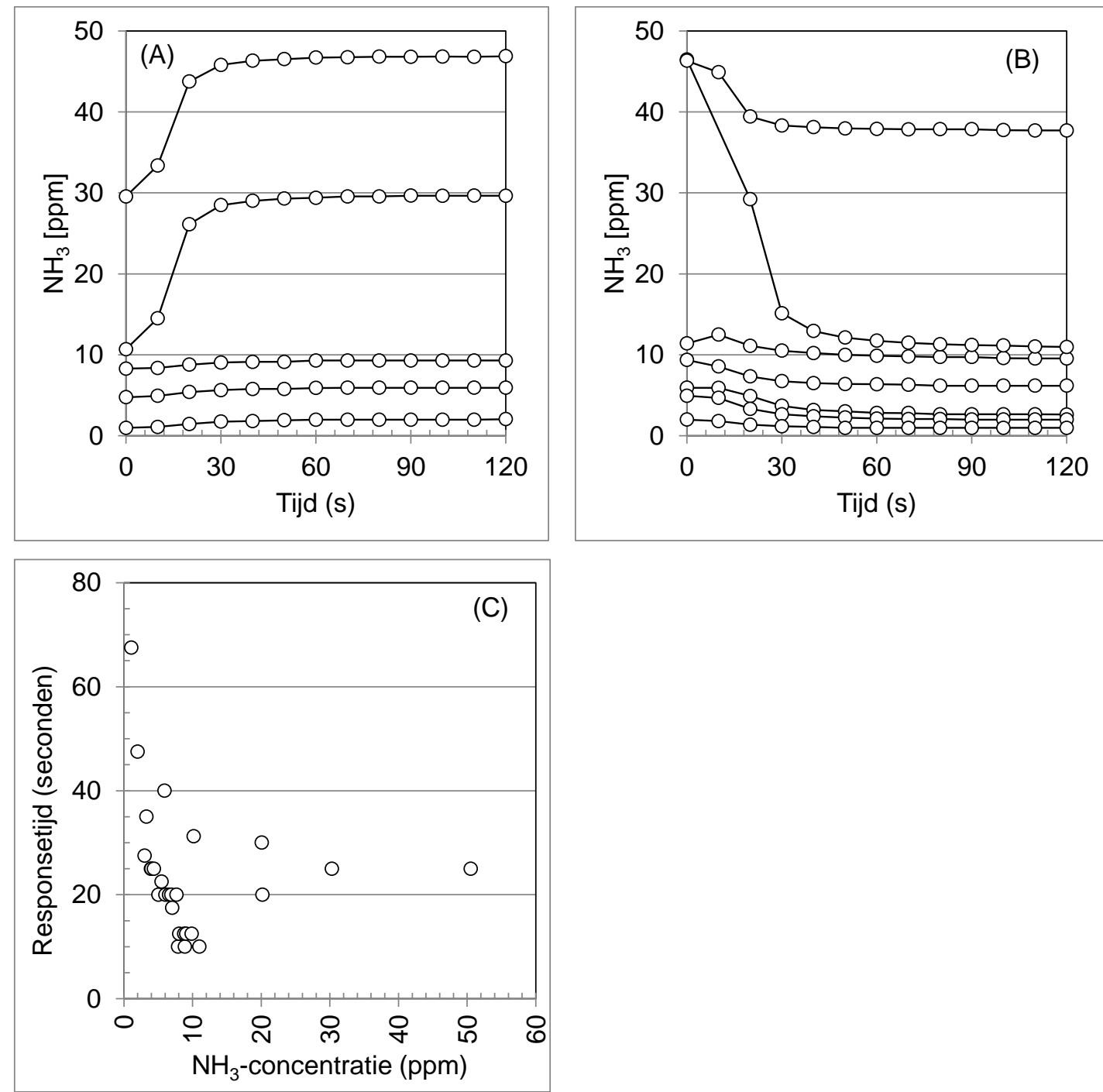

Figuur 3 Boven: reactie van de Dräger Polytron 8000 met FL-6813260 sensor voor $\mathrm{NH}_{3}$ op verschillende aangeboden concentraties in het lab, van lage naar hoge concentratie $(A)$ en van hoge naar lage concentratie $(B)$. Onder $(C)$ : responstijd (tijd die de sensor nodig heeft om een concentratie te meten die maximaal $10 \%$ verschilt van de aangeboden concentratie) als functie van de aangeboden $\mathrm{NH}_{3}$-concentratie. 


\subsection{Herhaalbaarheid van de sensoren}

Voor alle bruikbare metingen (zonder uitbijters) zijn kleine concentratieverschillen tussen sensoren geconstateerd. De medianen en de gemiddeldes van de verschillen tussen de gepaarde metingen zijn per meetpunt weergegeven in Tabel 6. Voor alle combinaties van meetlocaties/meetpunten (zie Tabel 6) wordt voldaan aan de randvoorwaarden voor acceptatie van de methode voor herhaalbaarheid van de metingen zoals beschreven in Hoofdstuk 2.3 volgens CEN/TS 14793 (2015). Voor het meetpunt buiten de melkveestal met meetwaarden kleiner dan $1 \mathrm{ppm}$ voldeed het berekende betrouwbaarheidsinterval ( $\mathrm{CL}-95 \%)$ voor de gepaarde meetverschillen net aan de grenswaarde van 0,1 ppm. Voor het meetbereik > $1 \mathrm{ppm}$ varieerden de berekende betrouwbaarheidsintervallen (procentuele gepaarde meetverschillen) tussen 3 en $8 \%$ en voldeden daarmee alle aan het $10 \%$ criterium.

Tabel 6 Herhaalbaarheid van metingen met verschillende sensoren en acceptatiewaarden volgens CEN/TS 14793 (2005)

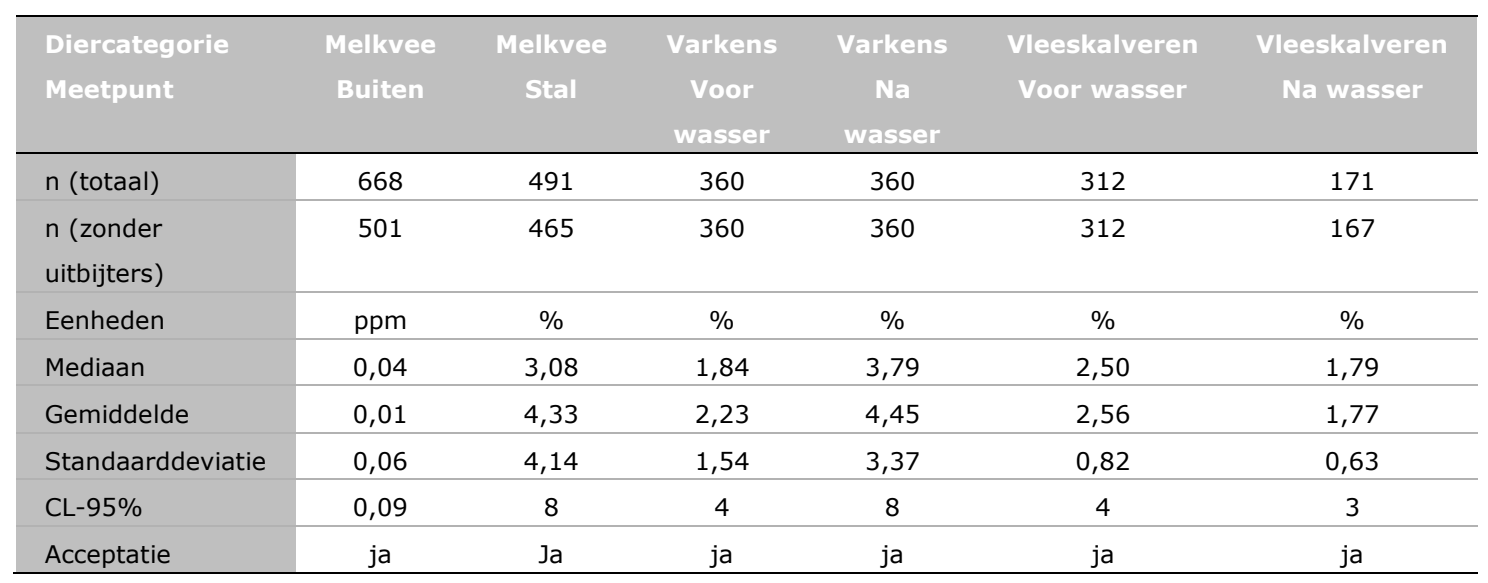

\subsection{Juistheid van de sensoren}

Voor het beoordelen van de gelijkwaardigheid in termen van juistheid zijn de onder praktijkomstandigheden verkregen meetresultaten van de AM vergeleken met gelijktijdig uitgevoerde SRM metingen. De vergelijking is gebaseerd op de gemiddeldes van duplo-metingen van zowel de AM als de SRM. Tabel 7 en Figuur 4 laten zien dat aan de randvoorwaarden voor gelijkwaardigheid van de methoden wordt voldaan (hoofdstuk 2.4) voor $\mathrm{NH}_{3}$-concentraties $>1 \mathrm{ppm}$. Voor lagere concentraties (<1ppm) wordt niet voldaan aan de randvoorwaarden beschreven in hoofdstuk 2.4. De regressielijn ligt net buiten de acceptatie-intervallen. Al met al kan geconcludeerd worden dat de Dräger Polytron 8000 met FL-6813260 sensor gelijkwaardig is aan de nat-chemische methode en toegepast mag worden voor het meten van $\mathrm{NH}_{3}$-concentraties $>1 \mathrm{ppm}$. Voor concentraties < $1 \mathrm{ppm}$ is deze methode minder nauwkeurig, doch toepasbaar als indicatieve praktijkmethode.

Tabel 7 Regressielijn voor de Dräger Polytron 8000 met FL-6813260 sensor t.o.v. nat-chemisch als referentiemethode. $\mathrm{NH}_{3}$-reference $=a * \mathrm{NH}_{3}$-sensor $+b$.

\begin{tabular}{cccc}
\hline Range & $\mathrm{A}$ & $\mathrm{b}$ & $\mathrm{R}^{2}$ \\
\hline $0-1 \mathrm{ppm}$ & 1.00 & -0.11 & 0.95 \\
$>1 \mathrm{ppm}$ & 1.02 & -0.34 & 0.99 \\
\hline
\end{tabular}



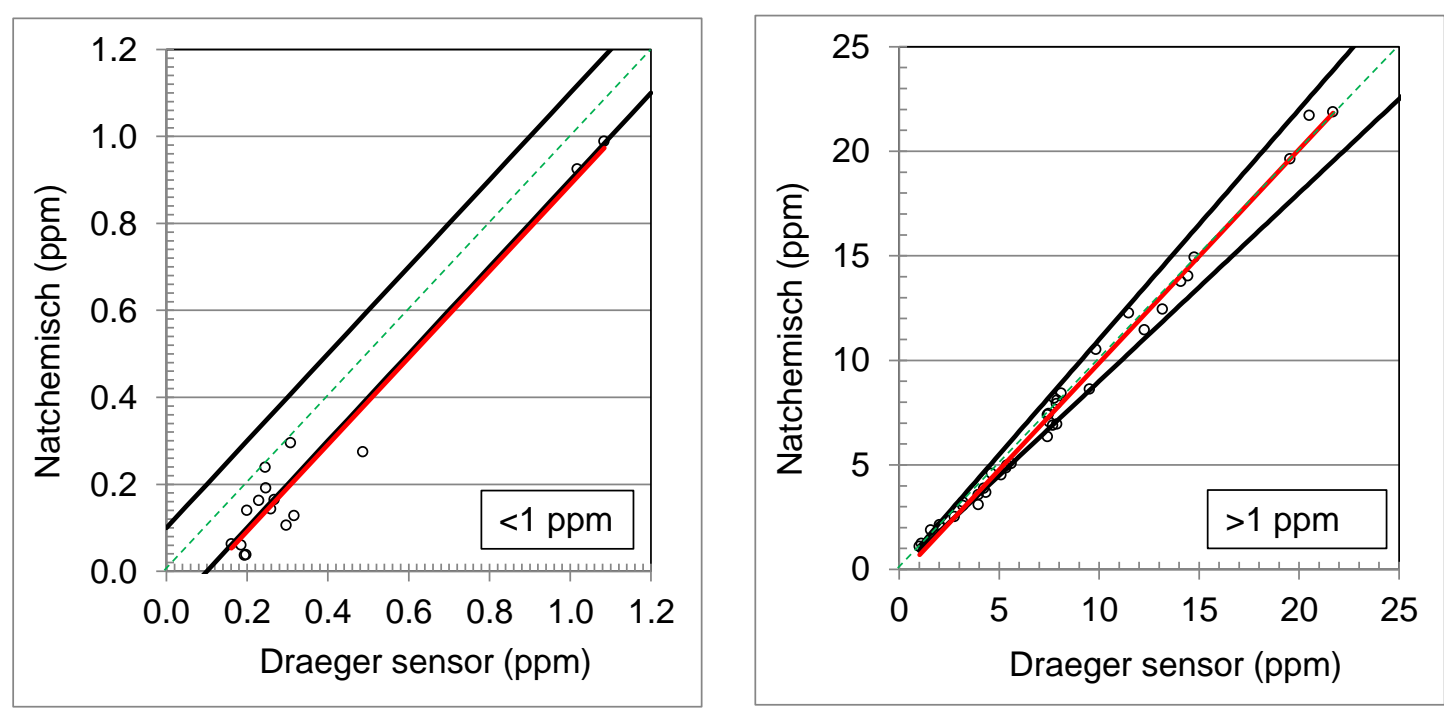

Figuur 4 Juistheid van metingen (praktijkmetingen) voor de Dräger Polytron 8000 met FL6813260 sensor voor $\mathrm{NH}_{3}$ t.o.v. nat-chemisch als referentiemethode. Regressielijn in rood, (10\%)acceptatie-intervallen in zwart.

\subsection{Mogelijke praktijktoepassingen}

De snelle responstijd van de sensor maakt het mogelijk om de Dräger Polytron 8000 met FL-6813260 sensor voor $\mathrm{NH}_{3}$ te kunnen inzetten in situaties waar $\mathrm{NH}_{3}$-concentraties met een hoge frequentie gemeten moeten worden.

\subsubsection{Luchtwassers}

Een mogelijke toepassing is het volgen van het rendement van luchtwassers (Figuur 5), zodat bijvoorbeeld storingen (resulterend in een lager rendement snel opgemerkt kunnen worden (zie Figuur $5 a)$. Daarnaast verschaffen dergelijke metingen nader inzicht in de variatie van het rendement die optreedt bij 'normaal' functionerende luchtwassers. Zo blijkt uit Figuur 5b dat er bij de combi (biologische) luchtwasser duidelijk sprake is van een dagcyclus in het rendement van de luchtwasser. De snelle responstijd van de sensor maakt het eveneens gemakkelijker om eventuele verbanden tussen het rendement van de wasser en management- of klimaatomstandigheden op te sporen. Hiervan wordt een aantal voorbeelden gegeven in Figuur 6. Uit Figuur 6B blijkt bijvoorbeeld dat het rendement van de combi (biologische) luchtwasser omlaag gaat bij een hoge temperatuur voor de wasser (= staltemperatuur). De verklaring hiervoor is dat er dan sprake is van een veel hoger luchtdebiet en dus korte luchtverblijftijd in de wasser (Melse e.a., 2012). De verwachting is dat dit niet, of in veel mindere mate, het geval is bij de chemische wasser, maar metingen bij hoge temperaturen (zie Figuur 6A) ontbreken op dit moment. 

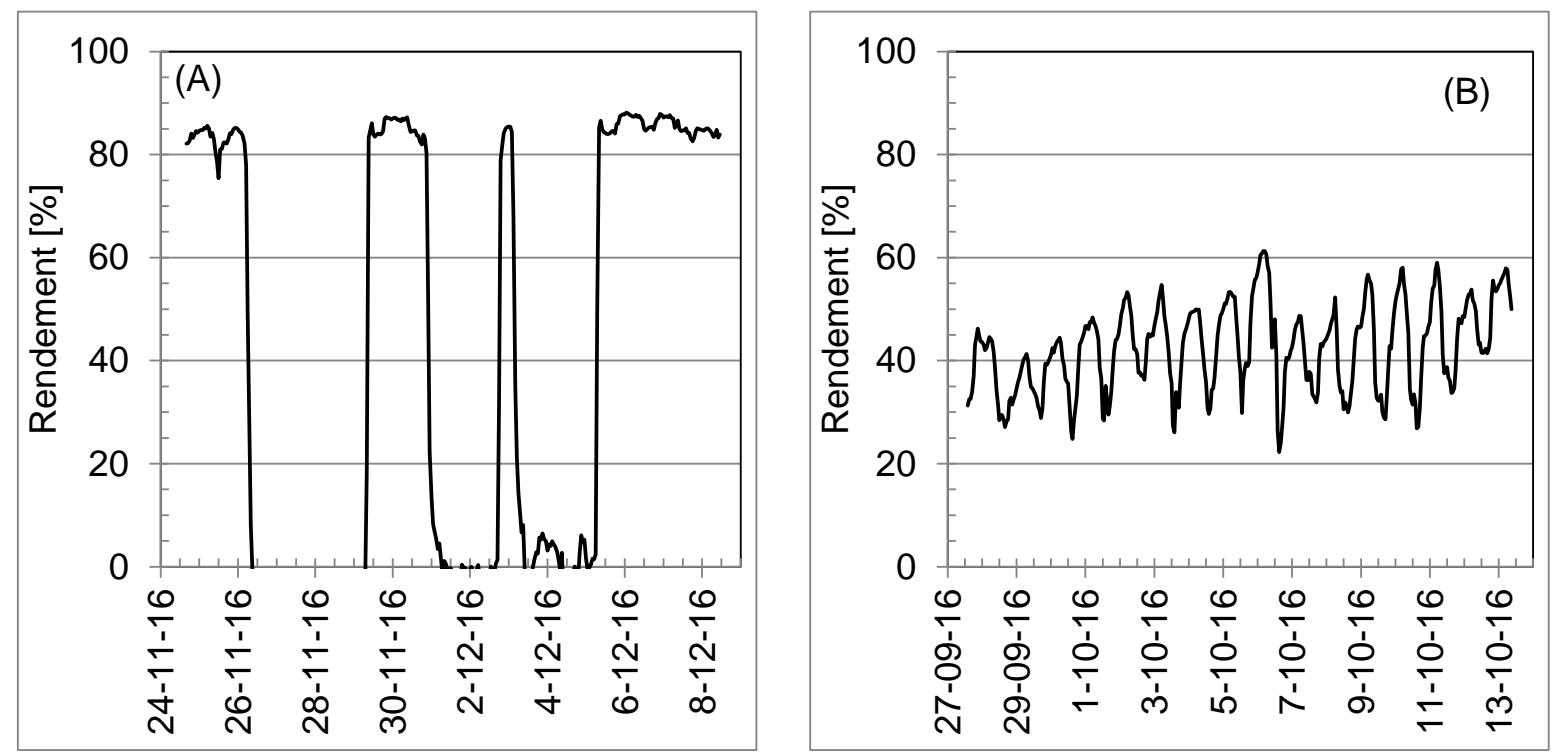

Figuur 5 Rendement van ( $A$ ) een chemisch en (B) een combi (biologisch) luchtwasser gemeten met de Dräger Polytron 8000 met FL-6813260 sensor voor $\mathrm{NH}_{3}$ onder praktijkomstandigheden bij meetlocatie 2 (varkensstal (mechanisch geventileerd) met gecombineerd luchtwasser) en meetlocatie 3 (vleeskalverenstal (mechanisch geventileerd) met chemisch luchtwasser).
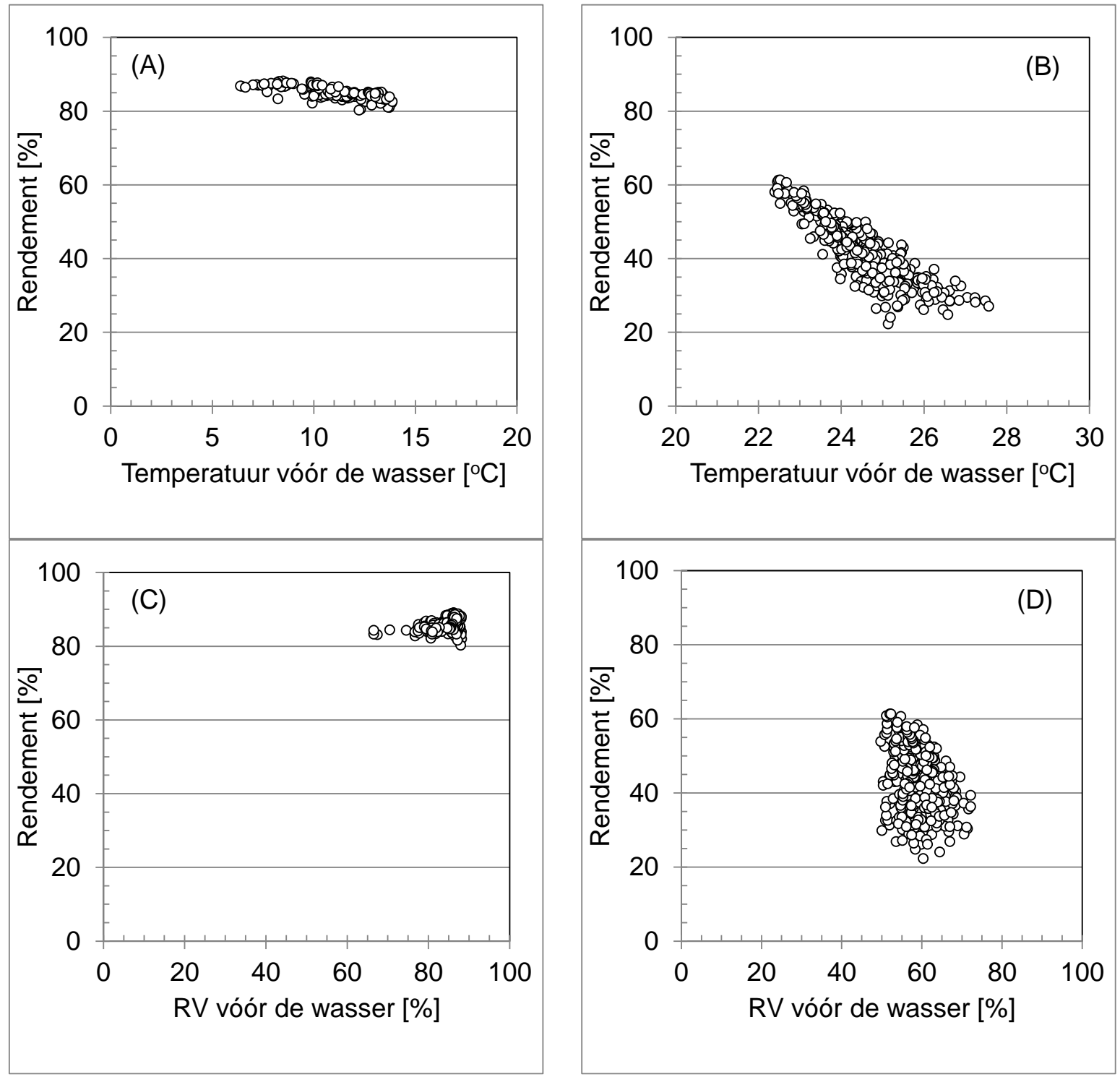

Figuur $6 \quad$ Boven: Relatie tussen het rendement van $(A)$ een chemisch en $(B)$ een combi (biologisch) luchtwasser en de temperatuur vóór de luchtwasser. Onder: Relatie tussen het rendement van $(C)$ een chemisch en $(D)$ een combi (biologisch) luchtwasser en de relatieve luchtvochtigheid ( $R V$ ) 
vóór de luchtwasser (gemeten met de AM). Bij de chemische luchtwasser zijn alleen de metingen met een werkend systeem (zonder storingen) weergegeven. De rendementsmetingen zijn uitgevoerd met de Dräger Polytron 8000 met FL-6813260 sensor.

Tenslotte laten Tabel 8 en Figuur 7 zien dat de rendementen van de luchtwassers die gemeten zijn m.b.v. de Dräger Polytron 8000 met FL-6813260 sensor voor $\mathrm{NH}_{3}$, vergelijkbaar zijn met die gemeten met een referentiemethode (nat-chemisch).

Tabel 8 Rendementen van de wassers (chemisch wasser bij varkens; combi (biologisch) wasser bij vleeskalveren. n.g.: niet gemeten.(1) wasser-storing.

\begin{tabular}{ccccc}
\hline \multirow{2}{*}{ Meting } & \multicolumn{2}{c}{ Rendement chemisch wasser (\%) } & \multicolumn{2}{c}{ Rendement combi-wasser (\%) } \\
\cline { 2 - 5 } & SRM & AM & SRM & AM \\
\hline 1 & 87.9 & 86.0 & 38.5 & 34.0 \\
2 & $43.2^{(1)}$ & $41.6^{(1)}$ & 44.7 & 44.7 \\
3 & $4.7^{(1)}$ & $0.0^{(1)}$ & 49.6 & 49.8 \\
4 & 89.0 & 87.4 & 57.5 & 43.5 \\
5 & 86.2 & 87.1 & 47.7 & 44.1 \\
6 & 83.4 & 85.2 & 43.5 & 49.6 \\
\hline
\end{tabular}

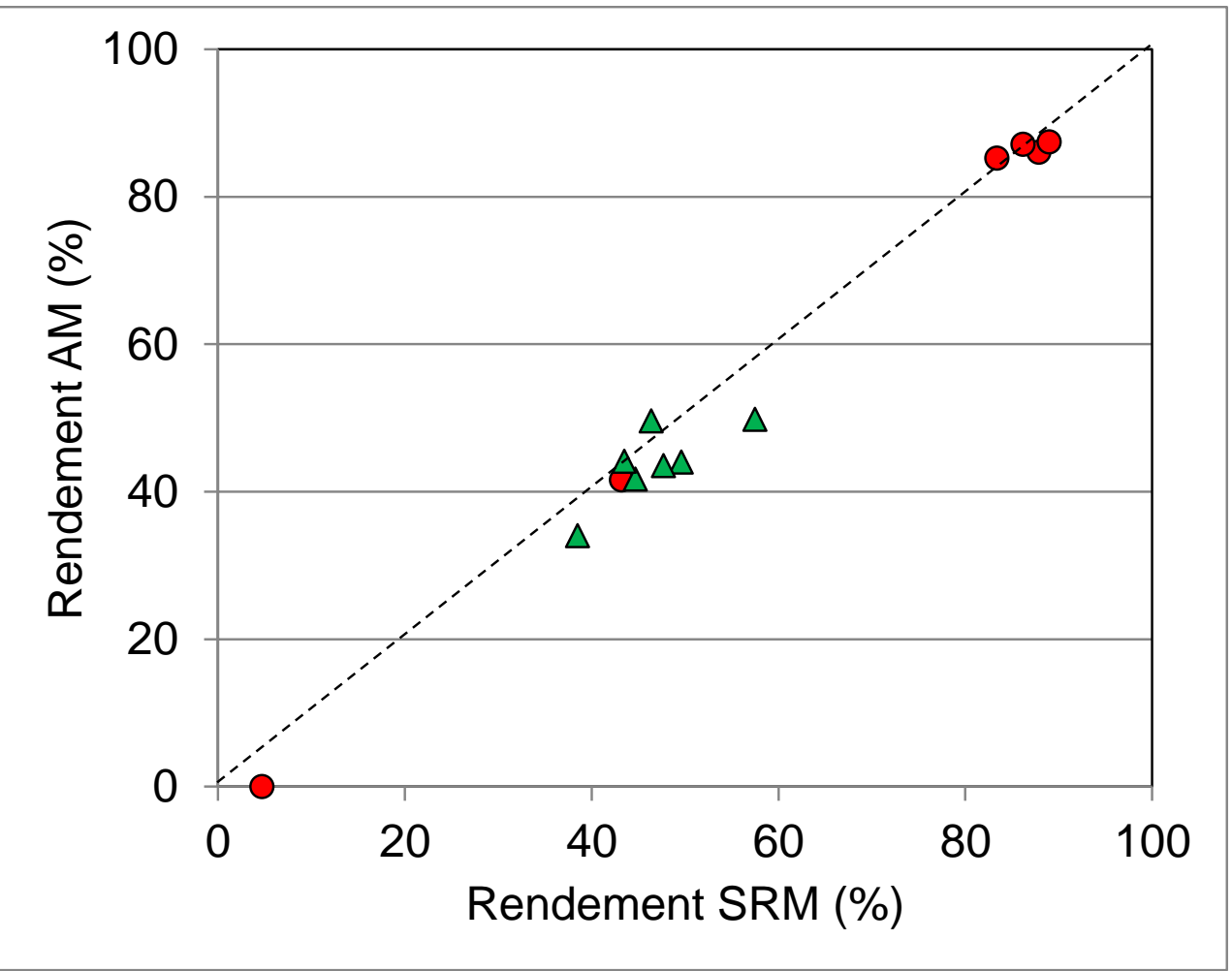

Figuur 7 Rendement van de luchtwassers gemeten met de SRM en de AM. Rood: chemische wasser; Groen: combi (biologisch) luchtwasser.

\subsubsection{Melkveestallen}

Een ander mogelijke toepassing is het gebruik van de $\mathrm{NH}_{3}$ sensor in een natuurlijk geventileerde melkveestal. Wanneer een (aantal) $\mathrm{NH}_{3}$ sensor(en) gebruikt wordt in combinatie met een (aantal) $\mathrm{CO}_{2}$ sensor(en), is het mogelijk om de actuele $\mathrm{NH}_{3}$ emissie van een stal te bepalen. De $\mathrm{CO}_{2}$ sensor wordt gebruikt om de ammoniakemissie van de stal te berekenen op basis van de gemeten concentratieverhoudingen $\mathrm{NH}_{3}: \mathrm{CO}_{2}$ en de geschatte $\mathrm{CO}_{2}$ productie (op basis van aantal dieren en productieniveau). Door de gemiddelde concentratieverhouding te vermenigvuldigen met de $\mathrm{CO}_{2}$ productie wordt de actuele $\mathrm{NH}_{3}$-emissie verkregen. Enerzijds schept dit de mogelijkheid om de werkelijke emissie van een melkveestal te meten (op dit moment wordt de emissie ingeschat op basis van emissiefactoren op basis van het gebruikte huisvestingssysteem), anderzijds wordt hierdoor de mogelijk geschapen om vanuit de overheid doelvoorschriften te hanteren in plaats van 
middelvoorschriften, zoals ook in de Inleiding reeds is besproken. Omdat de veehouder de actuele emissie kan aflezen, kan hij zelf maatregelen nemen qua management van stal en dieren om de emissie te verlagen. Vervolgens kan de veehouder meteen aflezen wat het effect van zijn handelen is. Wanneer de gemeten $\mathrm{NH}_{3}$ emissie automatisch wordt geregistreerd, kan de veehouder dan ook worden 'afgerekend' op de werkelijke emissie in plaats van op de vastgestelde emissiefactoren.

Het is denkbaar dat op deze wijze een grote stimulans zal uitgaan richting veehouderij en aanleverend bedrijfsleven om nieuwe emissiereducerende technieken te ontwikkelen en toe te passen (dit geldt overigens ook voor varkens en pluimvee). Het is dan namelijk niet meer nodig om deze technieken eerst via een (kostbare) procedure te testen alvorens deze mogen worden toegepast.

\subsubsection{Welzijn}

Tenslotte zou de sensor gebruikt kunnen worden in het kader van dierenwelzijn. Het is bekend dat hoge concentraties $\mathrm{NH}_{3}$ in het dierverblijf een negatief effect hebben op het dierenwelzijn, ook al bestaan er in Nederland geen normen voor een maximale $\mathrm{NH}_{3}$ concentratie in de stal. Door gebruik te maken van een dergelijke sensor kan de $\mathrm{NH}_{3}$ concentratie in bijvoorbeeld een varkens- of pluimveestal op een eenvoudige manier worden gemonitord. Wanneer de concentratie hoger wordt dan het gewenste maximum (bijv. 20 ppm), kunnen maatregelen genomen worden om de concentratie omlaag te brengen (in de praktijk zal dat meestal het verhogen van het ventilatiedebiet van de stal zijn). Hierbij moet bedacht worden dat er in de regel verschil zal zijn tussen de concentratie in de ventilatielucht van de stal en de concentratie op dierniveau. 


\section{$4 \quad$ Conclusies en aanbevelingen}

De resultaten van de validatiemetingen laten zien dat de Dräger Polytron 8000 met FL-6813260 sensor voor $\mathrm{NH}_{3}$ voldoet aan de eisen van de CEN/TS 14793 validatieprocedure voor het criterium herhaalbaarheid (instrument herhaalbaarheid) zowel in het meetbereik $0-1 \mathrm{ppm} \mathrm{NH}$ als in het meetbereik $>1 \mathrm{ppm} \mathrm{NH}$. De gelijkwaardigheid van de Dräger sensor in termen van juistheid t.o.v. de referentiemethode (nat-chemische bepaling), is eveneens onderzocht in genoemde meetbereiken. De juistheid werd getoetst door vast te stellen of de regressielijn met het verband tussen de resultaten van beide methodes binnen de voorgeschreven bandbreedtes van de $\mathrm{y}=\mathrm{x}$ lijn blijft. Voor het meetbereik met $\mathrm{NH}_{3}$-concentraties $>1 \mathrm{ppm}$ voldoet de Dräger sensor de eisen van de validatieprocedure. Voor het meetbereik met $\mathrm{NH}_{3}$-concentraties $<1 \mathrm{ppm}$ voldoet dit instrument niet aan de eisen voor gelijkwaardigheid. De regressielijn ligt hier net buiten de acceptatie-intervallen. Al met al kan het geconcludeerd worden dat de Dräger Polytron 8000 met FL-6813260 sensor gelijkwaardig is aan de nat-chemische methode en toegepast mag worden voor het meten van $\mathrm{NH}_{3}-$ concentraties $>1 \mathrm{ppm}$. Voor concentraties $<1 \mathrm{ppm}$ is deze methode minder nauwkeurig in termen van juistheid, doch toepasbaar als indicatieve praktijkmethode.

Uit de resultaten van dit onderzoek kan worden geconcludeerd dat de Dräger Polytron 8000 met FL6813260 sensor voor $\mathrm{NH}_{3}$ een snelle responstijd heeft (minder dan 1 minuut voor $\mathrm{NH}_{3}$-concentraties > $1 \mathrm{ppm}$, minder dan 2 minuten voor $\mathrm{NH}_{3}$-concentraties $<1 \mathrm{ppm}$ ) bij veranderingen in $\mathrm{NH}_{3}$ concentraties. Dit geldt zowel voor stijgingen in concentraties van laag naar hoog, als dalingen van hoog naar laag. Daarnaast ligt de laagste concentratie die de Dräger $\mathrm{NH}_{3}$-sensor FL-6813260 kan meten tussen 0,1-0,2 ppm. Op basis van de resultaten uit dit onderzoek wordt geadviseerd om een responstijd van 2 minuten toe te passen.

De snelle responstijd van de sensor maakt dit instrument geschikt voor metingen waar $\mathrm{NH}_{3}-$ concentraties met een hoge frequentie gemeten moeten worden. Hierbij kan gedacht worden aan het volgen van het rendement van luchtwassers (om storingen sneller te kunnen signaleren) of monitoring van de ammoniakconcentratie in varkens- en pluimveestallen in verband met dierenwelzijn. De gelijkwaardigheid met de referentiemethode komt tot uiting in de goede overeenstemming tussen de verwijderingsrendementen van beide methoden bij de metingen aan luchtwassers. De meetmethode is daarmee perspectiefvol als instrument voor bedrijfsmonitoring van het rendement van luchtwassers. Daarnaast biedt de meetmethode perspectief om (in combinatie met een $\mathrm{CO}_{2}$ sensor) gebruikt te worden voor het meten van de actuele ammoniakemissie van natuurlijk geventileerde rundveestallen. Hierdoor zou wellicht de mogelijkheid worden geschapen om wat betreft emissiereductie van ammoniak uit stallen een beweging te maken van middelvoorschriften naar doelvoorschriften. 


\section{Literatuur}

CEN/TS 14793 (2005). Stationary source emission - Intralaboratory validation procedure for an alternative method compared to a reference method.

Mosquera, J., J.P.M. Ploegaert, G.C.C. Kupers (2017). Determination of ammonia concentrations from agricultural sources - Reference method using gas washing. Wageningen UR Livestock Research Rapport (in voorbereiding).

Melse, R.W. ; Ploegaert, J.P.M. ; Ogink, N.W.M. (2012). Biotrickling filter for the treatment of exhaust air from a pig rearing building: Ammonia removal performance and its fluctuations. Biosystems Engineering 113 (3). - p. 242 - 252.

Melse, R.W., J.P.M. Ploegaert, N.W.M. Ogink (2016). Laboratory tests of Draeger Polytron 8000 with FL-6813260 sensor for NH3 measurement. Wageningen Livestock Research Report 972.

RVO (2015). Validatieprocedure voor het testen van de gelijkwaardigheid van alternatieve $\mathrm{NH3-}$ concentratie meetmethoden voor stalemissiemetingen. https://www.rvo.nl/sites/default/files/2015/09/Validatieprocedure\%20NH3\%20RVO\%2031-082015.pdf 


\section{Bijlage 1 Certificaten kalibratiecilinders}

\section{Certificaat 9,9 ppm gascilinder}

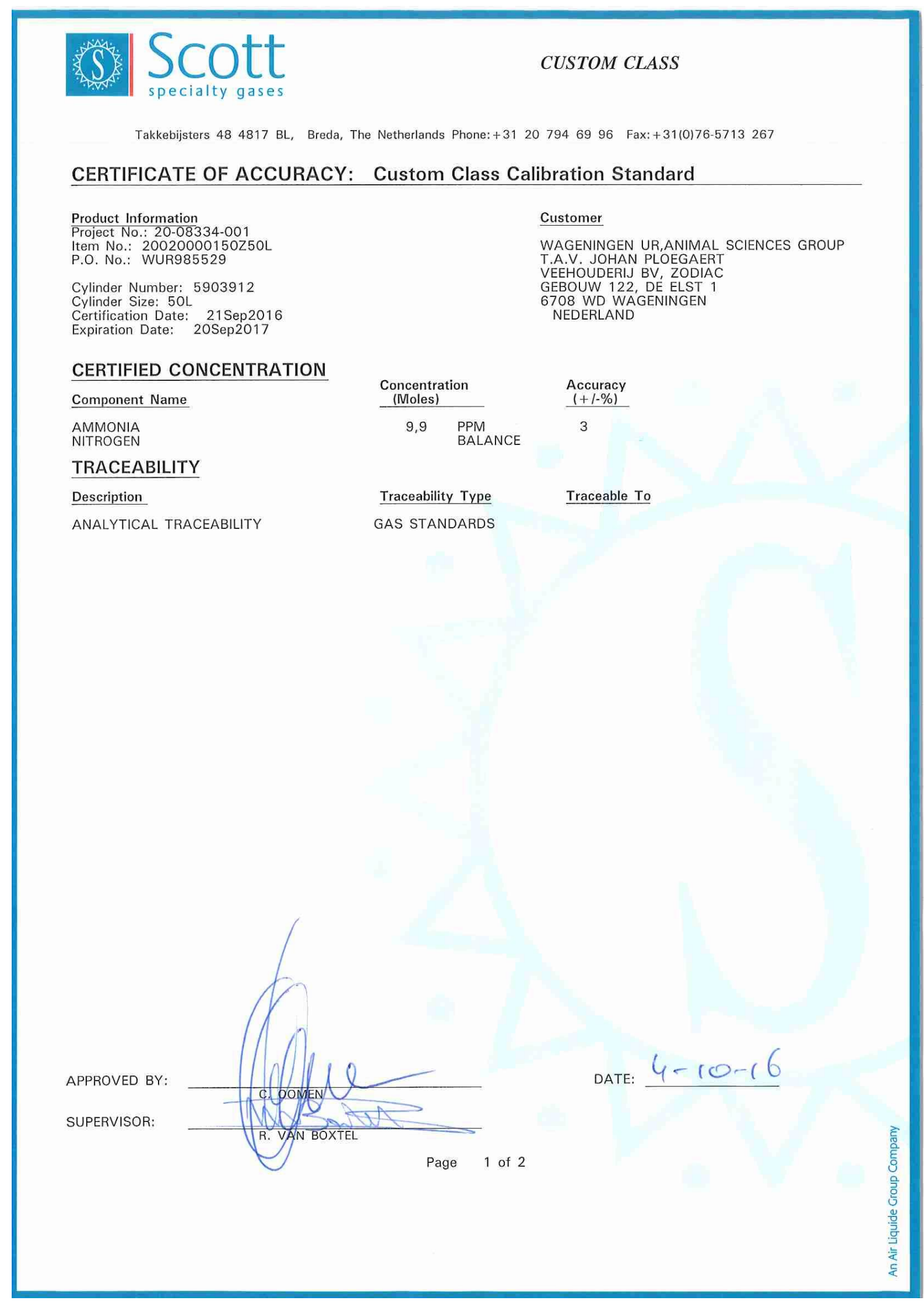




\begin{tabular}{|c|c|c|c|c|c|c|c|}
\hline SPECIFICATIONS & $\begin{array}{l}\text { Requested } \\
\text { Concentration } \\
\text { (Moles) }\end{array}$ & $\begin{array}{c}\text { Gravimetric } \\
\text { Concentration } \\
\text { (Moles) }\end{array}$ & $\begin{array}{c}\text { Analyzed } \\
\text { Concentration } \\
\text { (Moles) }\end{array}$ & $\begin{array}{c}\text { Blend } \\
\text { Tolerance } \\
\text { Result } \\
(+1-\%)\end{array}$ & $\begin{array}{c}\text { Blend } \\
\text { Process } \\
\text { Accuracy } \\
\text { Result } \\
(+t-\%)\end{array}$ & $\begin{array}{c}\text { Analytical } \\
\text { Accuracy } \\
\text { Result } \\
(+1-\%)\end{array}$ & $\begin{array}{c}\text { Interlocking } \\
\text { Result } \\
\{+1-\%)\end{array}$ \\
\hline $\begin{array}{l}\text { AMMOONIA } \\
\text { NITROBENA }\end{array}$ & 10 & $\mathrm{~N} / \mathrm{A}$ & 9,9 & 1,0 & $N / \bar{A}$ & 3,00 & $\mathrm{~N} / \mathrm{A}$ \\
\hline
\end{tabular}

TRACEABILITY

Analytical Traceability

$\frac{\text { Type/SRM No. }}{\text { SRS CSTD }} \frac{\text { Expiration Date }}{21 \text { Sep2016 }} \quad \frac{\text { Cylinder Number }}{\text { D1GTFO }} \quad \frac{\text { Concentration }}{24,99 \mathrm{PPM}} \quad \frac{\text { Component }}{\text { AMMMONIA }}$

Instrumentation

Instrument/Model/Serial\# TPAT-ATHRD PARTY ANAI.YSIS

PHYSICAL PROPERTIES

Cylinder Size: $50 \mathrm{~L}$

Analytical Principle

Analytical Mathod $2158 p 2016$ TPA

150 BAR

Expiration Date: 20Sep2017

Valve Connection: DIN-5

Min. Cyl. Pressure: 5 BAR

\section{SPECIAL HANDLING INSTRUCTIONS}

If a dew point is listed, do not use or store cylinder at or below the stated dew point temperature. Possible condensation of heavier components could result, In the event the cylinder has been exposed to temperatures at or below the dew point, place the cylinder in heated area for 24 hours and then roll cylnder for 15 minutes to remix.

Use of calibration standards at or below the stated dew point temperature may result in calibration error. 


\section{CERTIFICATE OF ACCURACY: Custom Class Calibration Standard}

Product Information

Project No.: 20-97567-002

Item No.: 20020000150Z50L

P.O. No.: WUR728325

Cylinder Number: 5902857

Cylinder Size: 50L

Certification Date: 05May2014

Expiration Date: 04May2015

\section{CERTIFIED CONCENTRATION}

Component Name

\section{AMMONIA}

NITROGEN

\section{TRACEABILITY}

Description

ANALYTICAL TRACEABILITY

\section{Customer}

WAGENINGEN UR,ANIMAL SCIENCES GROUP T.A.V. JOHAN PLOEGAERT

VEEHOUDERIJ BV

VIJFDE POLDER

6708 WC WAGENINGEN

NEDERLAND
Concentration

(Moles)

11,0 PPM

BALANCE

Traceability Type

GAS STANDARDS

\section{Accuracy}

$(+1-\%)$

3

Traceable To

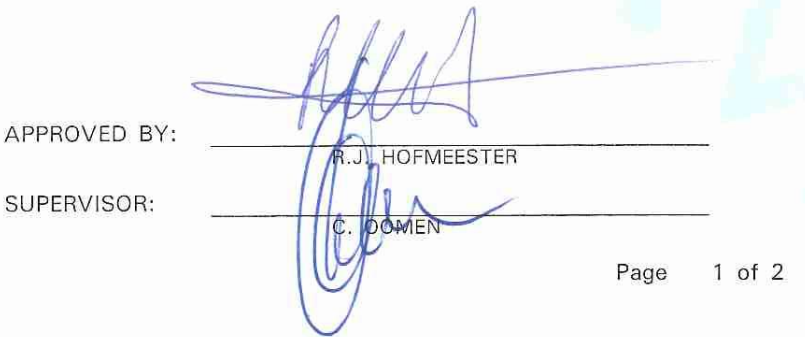




\begin{tabular}{|c|c|c|c|c|c|c|c|}
\hline SPECIFICATIONS & $\begin{array}{c}\text { Requested } \\
\text { Concentration } \\
\text { (Moles) }\end{array}$ & $\begin{array}{c}\text { Gravimatric } \\
\text { Concentration } \\
\text { (Moles) }\end{array}$ & $\begin{array}{c}\text { Analyzed } \\
\text { Concentration } \\
\text { \{Moles\} }\end{array}$ & $\begin{array}{c}\text { Blend } \\
\text { Tolerance } \\
\text { Result } \\
(+1-\%)\end{array}$ & $\begin{array}{c}\text { Blend } \\
\text { Process } \\
\text { Accuracy } \\
\text { Result } \\
\{+1-\% \mid\end{array}$ & $\begin{array}{c}\text { Analytical } \\
\text { Accuracy } \\
\text { Resutt } \\
(+1-\% \%)\end{array}$ & $\begin{array}{c}\text { Interlocking } \\
\text { Result } \\
(+1-\%) \\
\end{array}$ \\
\hline $\begin{array}{l}\text { AMYONIA, } \\
\text { NITROGES }\end{array}$ & PEM & $\mathrm{N} / \mathrm{A}$ & 11,0 & 10,0 & $\mathrm{~N} / \mathrm{A}$ & 3,00 & $N / A$ \\
\hline
\end{tabular}

\section{TRACEABILITY}

Analytical Traceability

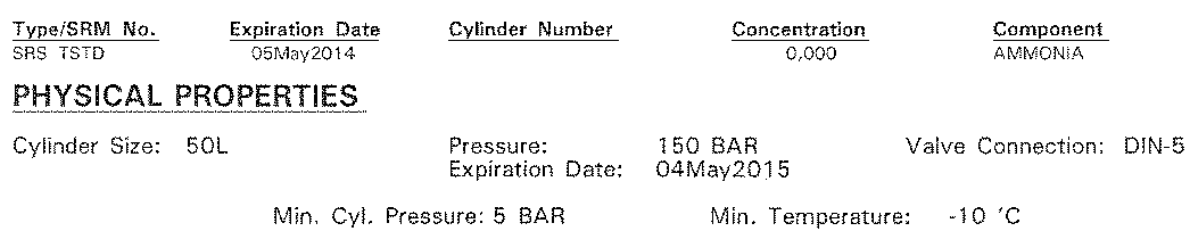

\section{SPECIAL HANDLING INSTRUCTIONS}

Do not use or store cylinder at or below the stated dew point temperature. Possible condensation of heavier components could result. In the event the cylinder has been exposed to temperatures at or below the dew point, place cylinder in heated area for 24 hours and then roll cylinder for 15 minutes to remix.

Use of calibration standards at or below dew point temperature may result in calibration error. 
Takkebijsters 484817 BL, Breda, The Netherlands Phone:+31/0)76-5711 828 Fax:+31(0)76-5713 267

\section{CERTIFICATE OF ACCURACY: Custom Class Calibration Standard}

Product Information

Project No.: 20-01957-002

Item No:: $20020000150 Z 50$

P.O. No.: WUR837436

Cylinder Number: 5902919

Cylinder Size: $50 \mathrm{~L}$

Certification Date: 30Apr2015

Expiration Date: 29Apr2018

\section{CERTIFIED CONCENTRATION}

Component Name

AMMONIA

TRACEABILITY

Description

ANALYTICAL TRACEABILITY

\section{Customer}

WAGENINGEN UR,ANIMAL SCIENCES GROUP ATTN: JOHAN PLOEGAERT VEEHOUDERIJ BV, ZODIAC GEBOUW 122, DE ELST 6708 WD WAGENINGEN

NEDERLAND
Concentration (Moles)

101, PPM BALANCE

Traceability Type GAS STANDARDS

\section{Accuracy}

$(+1-\%)$

1

Traceable To
DATE: $01-05-2015$

SUPERTSOR:

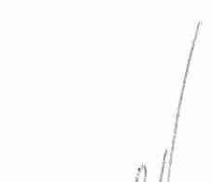

APPROVED BY:

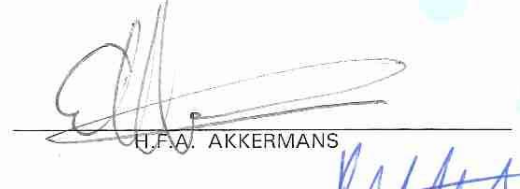

SUPERVISOR:

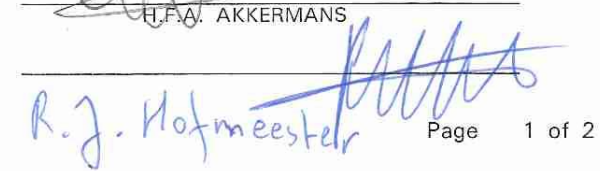




\section{SPECIFICATIONS}

\begin{tabular}{|c|c|c|c|c|c|c|c|}
\hline Component Name & $\begin{array}{c}\text { Requested } \\
\text { Concentration } \\
\text { (Moles) }\end{array}$ & $\begin{array}{c}\text { Gravimetric } \\
\text { Concentration } \\
\text { (Moles) }\end{array}$ & $\begin{array}{c}\text { Analyzed } \\
\text { Concentration } \\
\text { (Moles) }\end{array}$ & $\begin{array}{c}\text { Tolerance } \\
\text { Result } \\
(+1-\%)\end{array}$ & $\begin{array}{c}\text { Accuracy } \\
\text { Result } \\
(+1-\%)\end{array}$ & $\begin{array}{c}\text { Accuracy } \\
\text { Result } \\
(+1-\%)\end{array}$ & $\begin{array}{c}\text { Interlocking } \\
\text { Result } \\
(+1-\%)\end{array}$ \\
\hline $\begin{array}{l}\text { AYWOHA } \\
\text { NIIROCERN }\end{array}$ & 100 & $\mathrm{~N} / \mathrm{A}$ & 202. & 1,0 & $\mathrm{~N} / \mathrm{A}$ & 1,00 & $\mathrm{~N} / \mathrm{A}$ \\
\hline
\end{tabular}

\section{TRACEABILITY}

Analytical Traceability

\begin{tabular}{|c|c|c|c|c|}
\hline$\frac{\text { Type/SRM No. }}{\text { SkS "STD }}$ & $\frac{\text { Expiration Date }}{30 \mathrm{Apr} 2015}$ & Cylinder Number & $\frac{\text { Concentration }}{0,000}$ & Component \\
\hline \multicolumn{5}{|c|}{ PHYSICAL PROPERTIES } \\
\hline Cylinder Size: & $50 \mathrm{~L}$ & $\begin{array}{l}\text { Pressure: } \\
\text { Expiration Date: }\end{array}$ & $\begin{array}{l}\text { 150 BAR } \\
29 \text { Apr } 2018\end{array}$ & Valve Connection: \\
\hline
\end{tabular}

\section{SPECIAL HANDLING INSTRUCTIONS}

If a dew point is listed, do not use or store cylinder at or below the stated dew point temperature.

Possible condensation of heavier components could result. In the event the cylinder has been exposed to

temperatures at or below the dew point, place the cylinder in heated area for 24 hours and then roll

cylinder for 15 minutes to remix.

Use of calibration standards at or below the stated dew point temperature may result in calibration error. 


\section{Bijlage 2 Certificaten Signal 821}

Kalibratie (2015)

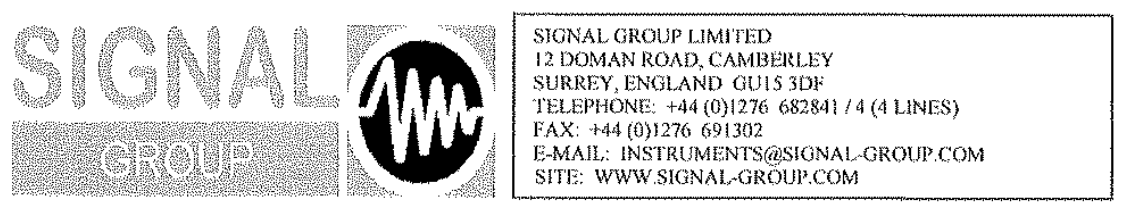

\section{CERTIFICATE OF CALIBRATION}

CONSIGNEE

Wageningen

\section{ORDER NUMBER}

W/O NUMBER

DATE OF CALIBRATION

$01 / 12 / 2015$

\begin{tabular}{|c|c|c|}
\hline DESCRIPTION OF GOODS & SERIAL NO & REMARKS \\
\hline 821S gas divider & 4789 & \\
\hline
\end{tabular}

\section{CALIBRATION RESULTS}

\begin{tabular}{|c|c|}
\hline DIVIDER SETTING & ACTUAL RESULT \\
\hline $100.00 \%$ & 100.00 \\
\hline $90.00 \%$ & 90.00 \\
\hline $80.00 \%$ & 79.92 \\
\hline $70.00 \%$ & 69.93 \\
\hline $60.00 \%$ & 60.04 \\
\hline $50.00 \%$ & 50.06 \\
\hline $40.00 \%$ & 39.90 \\
\hline $30.00 \%$ & 30.02 \\
\hline $20.00 \%$ & 20.08 \\
\hline $10.00 \%$ & 10.12 \\
\hline $0.00 \%$ & 0.00 \\
\hline
\end{tabular}

CALIBRATION GAS DETAILS

\begin{tabular}{|c|c|c|c|}
\hline CALIBRATION GAS TYPE & SUPPLIER & CERTIFICATE No. & TRACEABLITY \\
\hline 1000ppm C3H8/air & BOC & 143495 & NPL \\
& & & \\
\hline
\end{tabular}

SIGNAL AUDIT PROCEDURE NUMBER TPB00101

UNCERTAINTY OF MEASUREMENT $+1-0.2 \%$ F.S.D.

Signal Group certifes that the materials and processes used in the calibration of the unit detailed above hereon unless otherwise stated conform in all respects to Signal Group Lid procedures and specifications

SIGNED

Roy Kinslow 


\section{CERTIFICATE OF CALIBRATION}

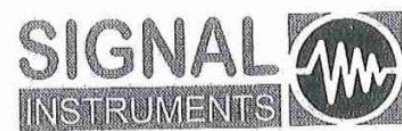

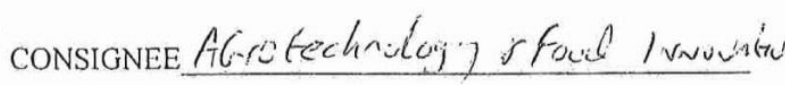

STANDARDS HOUSE, 12 DOMAN ROAD, CAMIBERLEY ORDER NUMBER SURREY, GU15 3DF, ENGLAND. TELEPHONE: $+44(0) 1276682841 / 6$ FACSIMILE: $+44(0) 1276691302$ EMIAIL: instruments@signal-group.com W/O NUMBER

DATE OF CALIBRATION $14 / 10 / 05$

Web: www.signal-group.com

Euerything for the Eutidsine Eugineer

\begin{tabular}{|c|l|l|}
\hline DESCRIPTION OF GOODS & SERIAL NO & REMARKS \\
\hline $8215 \mathrm{CAS}$ Divide. & 4789 & \\
\hline
\end{tabular}

\section{CALIBRATION RESULTS}

\begin{tabular}{|c|c|c|}
\hline DIVIDER SETTING & EXPECTED RESULT & ACTUAL RESULT \\
\hline $100.00 \%$ & & 100.3 \\
\hline $90.00 \%$ & & $8 \% .4$ \\
\hline $80.00 \%$ & $7 \% .82$ \\
\hline $70.00 \%$ & & 69.81 \\
\hline $60.00 \%$ & & $5 \% .85$ \\
\hline $50.00 \%$ & & 50.03 \\
\hline $40.00 \%$ & & $3 \% .85$ \\
\hline $30.00 \%$ & & 30.21 \\
\hline $20.00 \%$ & & $20.0 \%$ \\
\hline $10.00 \%$ & & 10.27 \\
\hline $0.00 \%$ & & $1 \% 0$ \\
\hline
\end{tabular}

\section{CALIBRATION GAS DETAILS}

\begin{tabular}{|c|c|c|c|}
\hline CALIBRATION GAS TYPE & SUPPLIER & CERTIFICATE No. & TRACEABILITY \\
\hline loxkplm Corll lain & messer- & HII40Z3 & $\checkmark \mathrm{fL}$ \\
\hline
\end{tabular}

SIGNAL AUDIT PROCEDURE NUMBER TPBO' $(!)$ UNCERTAINTY OF MEASUREMENT $+1-c \cdot 2 \% / \mathrm{f} \cdot \mathrm{s} \cdot \mathrm{l}$.

Signal Group certifies that the materials and processes used in the calibration of the unit detailed above hereon unless otherwise stated conform in all respects to Signal Group Ltd procedures ant specifications.

SIGNED

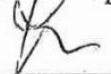




$\begin{array}{ll}\text { Aanvrager: } & \begin{array}{l}\text { IMAG - DLO } \\ \text { Mansholtlaan } 10-12 \\ \text { Wageningen }\end{array} \\ \text { Aangeboden: } & \begin{array}{l}\text { Een gas divider } \\ \text { fabrikaat } \quad: \text { Signal } \\ \text { type } \quad: 821 \\ \text { serie nummer }: 4789 \\ \text { bereik } \quad: 0-100 \%, \text { in stappen van } 10 \%\end{array}\end{array}$

Wijze van De door de gas divider gemaakte verdunningen zijn onderzocht met een referenonderzoek: tiemonitor welke gekalibreerd is met primaire standaard gasmengsels. Als nulgas is hoogzuivere stikstof aangeboden aan de gas divider. Als spangas is een mengsel gebruikt van $(1001 \pm 10) \cdot 10^{-6} \mathrm{~mol} / \mathrm{mol}$ stikstofmonoxide in stikstof. Bepaald is het werkelijke verdunningspercentage. De metingen werden uitgevoerd bij een omgevingstemperatuur van $21 \pm 0,5^{\circ} \mathrm{C}$.

Datum van

6 tot en met 20 september 1996

Resultaat:

Herleidbaar-

heid:

De resultaten staan vermeld op blad 2 van 2 .

De totale meetonzekerheid is gebaseerd op twee maal de standaardafwijking (2s).

De bij de kalibratie gebruikte gasmengsels zijn herleidbaar naar de primaire De bij de kalibratie gebruikte gasmengsels zijn herleid
standaard gasmengsels stikstofmonoxide in stikstof.

Datum en on24 september 1996

dertekening: 24 september 1996
NMi Van Syvinden Laboratorium B.V.

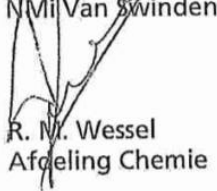

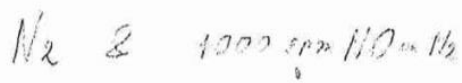

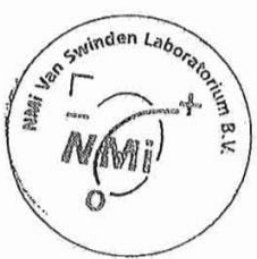

Nederlands Mleetinstitur Postbus 654

2600 AR Delft (NL)

Schoemakerstraat 97

2628 VK Delft

Telefoon (015) 2691500

Telefax (015) 2612971
Nederlands Meetinstituut N.V. (Ingeschreven bij) de

Werkmaatschappijen: NMI Certin B.V. (KvK nr. 33418) B.V. (KvK nr. 28703) NMi Jkwezen B.V. (KUK nr. 28700) NMi International BV. (KVK nr. 39170
Dit certificaat wordt verstrekt onder het voorbehoud dat generlel aansprakelijkheid wordt aanvaard en dat aanvrager vrijwaring geeft voor elke aansprakelijkheid jegens derden.

Reproduktie van het volledige certificaat is toegestaan. Gedeelten van dit certificaat mogen slechts worden
gereproduceerd na verkregen schriftelijke toestemming. 


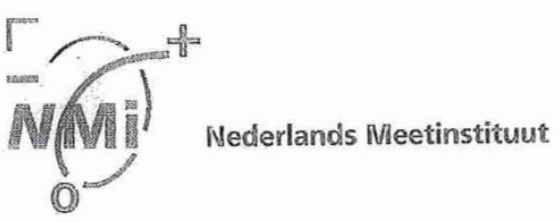

Nummer 316430-01

blad 2 van 2

Resultaat: Hieronder wordt het resultaat van de kalibratie weergegeven.

Meetbereik $0-100 \%$ in stappen van $10 \%$

\begin{tabular}{|c|c|}
\hline $\begin{array}{c}\text { Werkelijk verdunnings- } \\
\text { percentage }(\%)\end{array}$ & $\begin{array}{c}\text { ingesteld verdunnings } \\
\text { percentage }(\%)\end{array}$ \\
\hline \hline $10,05 \pm 0,10$ & 10 \\
$19,91 \pm 0,12$ & 20 \\
$29,86 \pm 0,12$ & 30 \\
$39,73 \pm 0,18$ & 40 \\
$49,93 \pm 0,20$ & 50 \\
$60,04 \pm 0,25$ & 60 \\
$69,88 \pm 0,25$ & 70 \\
$79,95 \pm 0,25$ & 80 \\
$89,99 \pm 0,25$ & 90 \\
\hline
\end{tabular}

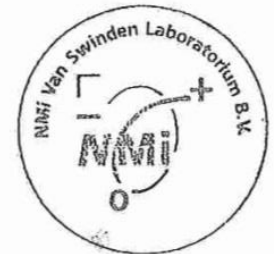




\section{Bijlage 3 Certificaat EPM 797-430}

Kalibratie-certificaat c02009-3

$\begin{aligned} \text { Aanvrager: } & \text { ASG Veehouderii B.V. } \\ & \begin{array}{l}\text { Postbus } 65 \\ 8200 \text { AB Lelystad }\end{array} \\ \text { Aangeboden: } & \text { Laboratoriumverdunner } \\ \text { Fabrikaat } & \text { EPM } \\ \text { Type } & 797-430 \\ \text { Serienummer } & \text { E } 77\end{aligned}$

Wijze van onderzoek: Het onderzoek werd uitgevoerd met $\mathrm{CO}$ als tracergas. De CO-concentraties werden gemeten met een gekalibreerde GFC CO-analyser. De verdunningen werden berekend uit de in en uitgaande $\mathrm{CO}$-gasconcentraties van het verdunningstoestel.

Omgevingscondities Het onderzoek is uitgevoerd bij een ruimtetemperatuur van $(21 \pm 2)^{\circ} \mathrm{C}$.

Datum van onderzoek: 17 maart 2009.

Resultaat: De resultaten en meetonzekerheden staan vermeld op blad 2.

Onzekerheid: De gerapporteerde onzekerheid is gebaseerd op de standaardonzekerheid vermenigvul digd met een dekkingsfactor $k=2$, welke overeenkomt met een betrouwbaarheidsinterval van ongeveer $95 \%$. De standaardonzekerheid is bepaald volgens EA-4/02.

Herleidbaarheid: De metingen zijn uitgevoerd met meetmiddelen waarvan de herleidbaarheid naar (inter)nationale standaarden is aangetoond ten overstaan van de Raad voor Accreditatie.

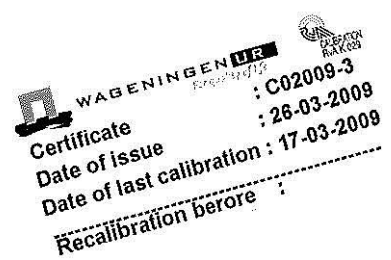

Reproductie van het volledige certificaat is toegestaan. Gedeelten mogen slechts worden gereproduceerd na schriftelijke toestemming van ASG Veehouderij,

Dit certificaat wordt verstrekt onder de voorwaarde dat ASG Veehouderii generlei aansprakelijkheid aanvaardt. 
Kalibratie-certificaat c02009-3

\begin{tabular}{cccccc}
\hline Instelling & Verdunning & & $\begin{array}{c}\text { Onzekerheid } \\
(\mathrm{k}=2) \\
H\end{array}$ & $\begin{array}{c}\text { Nauwkeurig- } \\
\text { heid } \\
H\end{array}$ & $\begin{array}{c}\text { Stabiliteit } \\
\%\end{array}$ \\
\hline 2.6 & 10.0 & +- & 0.03 & 0.008 & 0.24 \\
3.0 & 11.0 & $+/-$ & 0.01 & 0.008 & 0.28 \\
4.0 & 13.5 & $+/-$ & 0.06 & 0.005 & 0.22 \\
5.0 & 16.0 & $+/-$ & 0.08 & 0.004 & 0.19 \\
6.0 & 18.7 & $+1-$ & 0.15 & 0.003 & 0.23
\end{tabular}

Opmerkingen: Metingen conform NEN-EN 13725:2003. Uitgevoerd door JP. De laboratoriumverdunner werd met de hand bediend.

Wageningen UR Reproductie van het volledige certificaat is toegestaan. Gedeelten mogen slechts worden gereproduceerd na ASG Veehouderij B.V. Cluster MHE Wageningen

Bornsesteeg 59
6708 PD Wageningen schriftelijke toestemming van ASG Veehouderij.

Dit certificaat wordt verstrekt onder de voorwaarde dat ASG Veehouderij generlei aansprakelijkheid aanvaardt. Telefoon $+31(0) 317487276$

Telefax +31 (0) 317475347 


\section{Bijlage 4 Resultaten lab-kalibratie Dräger $\mathrm{NH}_{3}$-sensor FL-6813260}

Meetserie $1\left(\mathrm{NH}_{3}\right.$ werkelijk $\left.(\mathrm{ppm})=\mathrm{a} * \mathrm{NH}_{3} \operatorname{sensor}(\mathrm{ppm})+\mathrm{b}\right)$

\begin{tabular}{cccccccccc}
\hline & \multicolumn{3}{c}{$0-1 \mathrm{ppm}$} & \multicolumn{4}{c}{$1-10 \mathrm{ppm}$} & \multicolumn{3}{c}{$10-50 \mathrm{ppm}$} \\
\hline Sensor & $\mathrm{a}$ & $\mathrm{b}$ & $\mathrm{R}^{2}$ & $\mathrm{a}$ & $\mathrm{b}$ & $\mathrm{R}^{2}$ & $\mathrm{a}$ & $\mathrm{b}$ & $\mathrm{R}^{2}$ \\
\hline 1 & 0,81 & 0,08 & 0,98 & 0,92 & $-0,08$ & 0,99 & 1,12 & $-2,13$ & 1,00 \\
\hline 2 & 0,75 & 0,04 & 1,00 & 0,81 & $-0,14$ & 1,00 & 1,10 & $-3,86$ & 1,00 \\
\hline 3 & 0,89 & 0,29 & 1,00 & 0,91 & 0,24 & 1,00 & 1,00 & $-0,65$ & 1,00 \\
\hline 4 & 0,87 & 0,45 & 0,99 & 0,88 & 0,35 & 1,00 & 0,98 & $-0,70$ & 1,00 \\
\hline
\end{tabular}

Meetserie $2\left(\mathrm{NH}_{3}\right.$ werkelijk $\left.(\mathrm{ppm})=\mathrm{a} * \mathrm{NH}_{3} \operatorname{sensor}(\mathrm{ppm})+\mathrm{b}\right)$

\begin{tabular}{cccccccccc}
\hline & \multicolumn{3}{c}{$0-1 \mathrm{ppm}$} & \multicolumn{3}{c}{$1-10 \mathrm{ppm}$} & \multicolumn{3}{c}{$10-50 \mathrm{ppm}$} \\
\hline Sensor & $\mathrm{a}$ & $\mathrm{b}$ & $\mathrm{R}^{2}$ & $\mathrm{a}$ & $\mathrm{b}$ & $\mathrm{R}^{2}$ & $\mathrm{a}$ & $\mathrm{b}$ & $\mathrm{R}^{2}$ \\
\hline 1 & 0,85 & 0,11 & 0,98 & 0,94 & $-0,11$ & 1,00 & 1,13 & $-2,57$ & 1,00 \\
\hline 2 & 0,77 & 0,08 & 1,00 & 0,85 & $-0,14$ & 1,00 & 1,11 & $-3,80$ & 1,00 \\
\hline 3 & 0,82 & 0,35 & 1,00 & 0,93 & 0,36 & 1,00 & 0,97 & $-0,22$ & 1,00 \\
\hline 4 & 0,79 & 0,37 & 0,99 & 0,89 & 0,38 & 1,00 & 0,94 & $-0,29$ & 1,00
\end{tabular}

Meetserie $3\left(\mathrm{NH}_{3}\right.$ werkelijk $\left.(\mathrm{ppm})=\mathrm{a} * \mathrm{NH}_{3} \operatorname{sensor}(\mathrm{ppm})+\mathrm{b}\right)$

\begin{tabular}{cccccccccc}
\hline & \multicolumn{3}{c}{$0-1 \mathrm{ppm}$} & \multicolumn{3}{c}{$1-10 \mathrm{ppm}$} & \multicolumn{3}{c}{$10-50 \mathrm{ppm}$} \\
\hline Sensor & $\mathrm{a}$ & $\mathrm{b}$ & $\mathrm{R}^{2}$ & $\mathrm{a}$ & $\mathrm{b}$ & $\mathrm{R}^{2}$ & $\mathrm{a}$ & $\mathrm{b}$ & $\mathrm{R}^{2}$ \\
\hline 1 & 0,84 & 0,12 & 1,00 & 0,95 & $-0,02$ & 1,00 & 1,12 & $-2,54$ & 1,00 \\
\hline 2 & 0,69 & 0,14 & 1,00 & 0,84 & $-0,13$ & 1,00 & 1,05 & $-3,32$ & 0,99 \\
\hline 3 & 0,75 & 0,39 & 1,00 & 0,97 & 0,33 & 1,00 & 0,96 & 0,18 & 1,00 \\
\hline 4 & 0,74 & 0,35 & 0,99 & 0,92 & 0,21 & 1,00 & 0,93 & $-0,09$ & 1,00
\end{tabular}

Meetserie $4\left(\mathrm{NH}_{3}\right.$ werkelijk $\left.(\mathrm{ppm})=\mathrm{a} * \mathrm{NH}_{3} \operatorname{sensor}(\mathrm{ppm})+\mathrm{b}\right)$

\begin{tabular}{cccccccccc}
\hline & \multicolumn{3}{c}{$0-1 \mathrm{ppm}$} & \multicolumn{3}{c}{$1-10 \mathrm{ppm}$} & \multicolumn{3}{c}{$10-50 \mathrm{ppm}$} \\
\hline Sensor & $\mathrm{a}$ & $\mathrm{b}$ & $\mathrm{R}^{2}$ & $\mathrm{a}$ & $\mathrm{b}$ & $\mathrm{R}^{2}$ & $\mathrm{a}$ & $\mathrm{b}$ & $\mathrm{R}^{2}$ \\
\hline 1 & 0,84 & 0,10 & 0,99 & 0,95 & 0,06 & 1,00 & 1,10 & $-2,19$ & 1,00 \\
\hline 2 & 0,66 & 0,22 & 0,97 & 0,79 & 0,02 & 1,00 & 0,94 & $-2,60$ & 1,00 \\
\hline 3 & 0,82 & 0,39 & 0,99 & 0,96 & 0,35 & 1,00 & 0,97 & 0,06 & 1,00 \\
\hline 4 & 0,79 & 0,44 & 0,97 & 0,92 & 0,36 & 1,00 & 0,92 & 0,06 & 1,00 \\
\hline
\end{tabular}




\section{Bijlage $5 \quad \mathrm{NH}_{3}$-concentratiemetingen}

\begin{tabular}{|c|c|c|c|c|c|c|}
\hline $\begin{array}{c}\text { Meetseri } \\
\text { e }\end{array}$ & $\begin{array}{c}\text { Meetpun } \\
t\end{array}$ & $\begin{array}{l}\text { Metin } \\
\text { g }\end{array}$ & $\begin{array}{c}\text { Natchemisc } \\
\text { h }\end{array}$ & $\begin{array}{c}\text { Natchemisc } \\
\text { h }\end{array}$ & $\begin{array}{c}\text { Dräge } \\
\quad r\end{array}$ & $\begin{array}{c}\text { Dräge } \\
\mathbf{r}\end{array}$ \\
\hline \multirow{14}{*}{1} & \multirow{7}{*}{ Stal } & 1 & 3,1 & 3,1 & 4,0 & (2) \\
\hline & & 2 & 3,7 & 3,7 & 4,3 & 4,3 \\
\hline & & 3 & 3,9 & 3,8 & 4,2 & 4,2 \\
\hline & & 4 & 3,5 & 3,6 & 4,0 & (2) \\
\hline & & 5 & 4,8 & 4,9 & 5,3 & (2) \\
\hline & & 6 & 4,9 & 5,0 & 5,4 & (2) \\
\hline & & 7 & 2,5 & 2,5 & 2,8 & (2) \\
\hline & \multirow{7}{*}{ Buiten } & 8 & 0,15 & 0,14 & 0,26 & (2) \\
\hline & & 9 & 0,07 & 0,06 & 0,16 & (2) \\
\hline & & 10 & 0,16 & 0,17 & 0,23 & (2) \\
\hline & & 11 & 0,20 & 0,18 & 0,25 & (2) \\
\hline & & 12 & 0,30 & 0,29 & 0,33 & 0,28 \\
\hline & & 13 & 0,24 & 0,24 & 0,26 & 0,23 \\
\hline & & 14 & 0,16 & 0,12 & 0,20 & (2) \\
\hline \multirow{14}{*}{2} & \multirow{7}{*}{$\begin{array}{l}\text { Vóór de } \\
\text { wasser }\end{array}$} & 15 & 14,0 & 14,0 & 14,5 & 14,4 \\
\hline & & 16 & 12,9 & 12,0 & 12,9 & 13,5 \\
\hline & & 17 & 13,7 & 13,8 & 13,8 & 14,4 \\
\hline & & 18 & 15,0 & 14,8 & 14,5 & 15,1 \\
\hline & & 19 & 22,0 & 21,7 & 21,5 & 21,9 \\
\hline & & 20 & 21,6 & 21,9 & 20,4 & 20,6 \\
\hline & & 21 & 19,8 & 19,5 & 19,4 & 19,7 \\
\hline & \multirow{7}{*}{$\begin{array}{l}\text { Na de } \\
\text { wasser }\end{array}$} & 22 & 8,6 & 8,7 & 9,5 & 9,6 \\
\hline & & 23 & 7,1 & 6,7 & 7,8 & 7,6 \\
\hline & & 24 & 12,8 & 6,9 & 8,0 & 7,8 \\
\hline & & 25 & $11,9^{(1)}$ & 6,3 & 7,5 & 7,3 \\
\hline & & 26 & $17,0^{(1)}$ & 11,5 & 12,8 & 11,7 \\
\hline & & 27 & 13,0 & 11,5 & 12,0 & 11,0 \\
\hline & & 28 & $15,8^{(1)}$ & 10,5 & 10,3 & 9,4 \\
\hline
\end{tabular}

(1) Contaminatie in wasflessen, schuim in wasflessen na roeren. Data niet meegenomen in analyse

(2) Door storing, data niet beschikbaar 


\begin{tabular}{|c|c|c|c|c|c|c|}
\hline $\begin{array}{c}\text { Meetseri } \\
e\end{array}$ & $\begin{array}{c}\text { Meetpun } \\
t\end{array}$ & $\begin{array}{c}\text { Metin } \\
\text { g }\end{array}$ & $\begin{array}{c}\text { Natchemisc } \\
\text { h }\end{array}$ & $\begin{array}{c}\text { Natchemisc } \\
\text { h }\end{array}$ & $\begin{array}{c}\text { Dräge } \\
r\end{array}$ & $\underset{r}{\text { Dräge }}$ \\
\hline \multirow{14}{*}{3} & \multirow{7}{*}{ Stal } & 29 & 2,0 & 2,0 & 2,0 & (2) \\
\hline & & 30 & 3,0 & 3,1 & 3,2 & (2) \\
\hline & & 31 & 5,0 & 5,1 & 5,6 & (2) \\
\hline & & 32 & 1,9 & 1,9 & 1,5 & 1,6 \\
\hline & & 33 & 4,6 & 4,4 & 5,1 & (2) \\
\hline & & 34 & 3,2 & 3,2 & 3,2 & (2) \\
\hline & & 35 & 2,1 & 2,1 & 2,0 & (2) \\
\hline & \multirow{7}{*}{ Buiten } & 36 & 0,17 & 0,16 & 0,24 & 0,30 \\
\hline & & 37 & 0,05 & 0,07 & 0,14 & 0,23 \\
\hline & & 38 & 0,03 & 0,04 & 0,14 & 0,25 \\
\hline & & 39 & 0,05 & 0,02 & 0,14 & 0,25 \\
\hline & & 40 & 0,29 & 0,26 & 0,45 & 0,53 \\
\hline & & 41 & 0,13 & 0,13 & 0,26 & 0,37 \\
\hline & & 42 & 0,11 & 0,10 & 0,25 & 0,35 \\
\hline \multirow{12}{*}{4} & \multirow{6}{*}{$\begin{array}{l}\text { Vóór de } \\
\text { wasser }\end{array}$} & 43 & 8,3 & 8,1 & 7,6 & 7,9 \\
\hline & & 44 & 8,1 & 8,1 & 7,8 & 8,0 \\
\hline & & 45 & 7,4 & 7,3 & 7,4 & 7,5 \\
\hline & & 46 & 8,4 & 8,5 & 8,0 & 8,2 \\
\hline & & 47 & 8,0 & 7,9 & 7,8 & 7,9 \\
\hline & & 48 & 7,5 & 7,4 & 7,4 & 7,5 \\
\hline & \multirow{6}{*}{$\begin{array}{l}\text { Na de } \\
\text { wasser }\end{array}$} & 49 & (1) & 1,0 & 1,0 & 1,2 \\
\hline & & 50 & 4,5 & 4,7 & 4,6 & 4,7 \\
\hline & & 51 & 7,1 & 7,0 & 7,6 & 7,4 \\
\hline & & 52 & 0,9 & 1,0 & 1,0 & (2) \\
\hline & & 53 & 1,0 & 1,2 & 1,0 & (2) \\
\hline & & 54 & 1,2 & 1,3 & 1,1 & (2) \\
\hline
\end{tabular}

(1) Geen meting, door vacuüm in de fles, bevroren in de buitenleiding.

(2) Door storing, data niet beschikbaar 

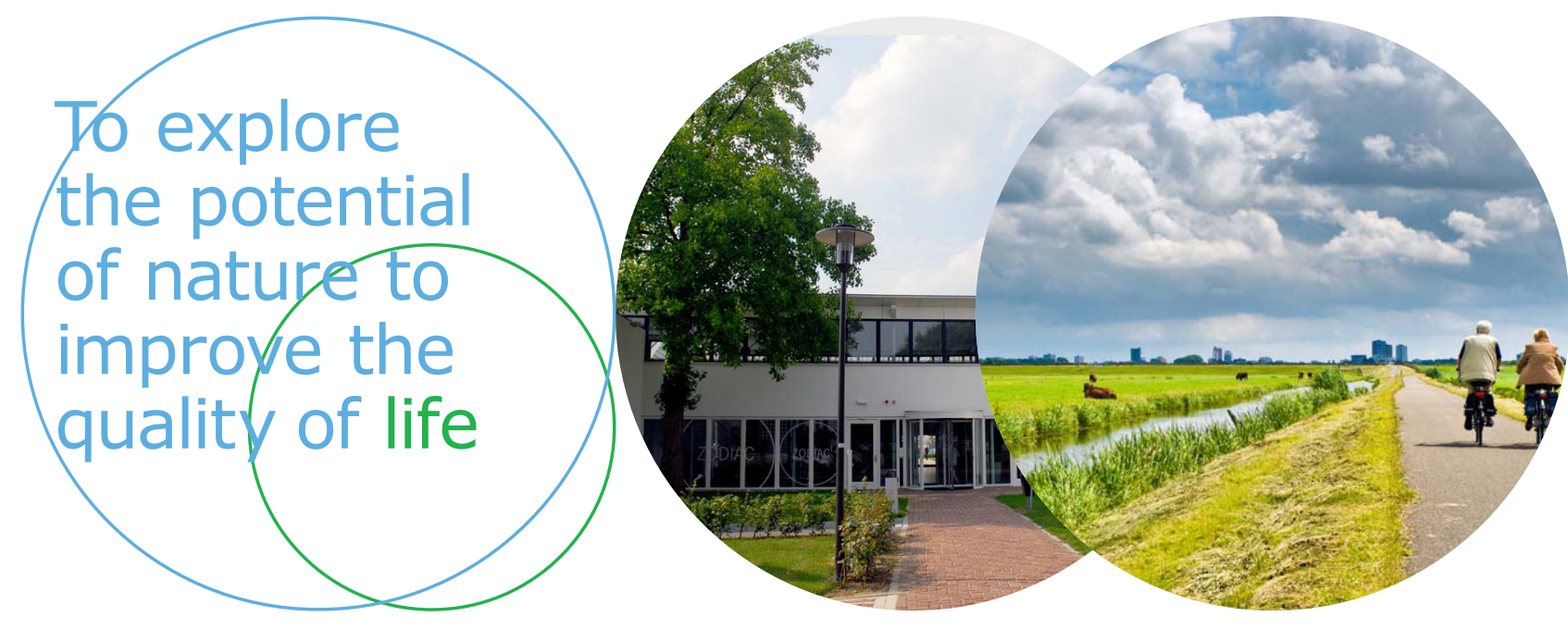

Wageningen Livestock Research Postbus $3386700 \mathrm{AH}$ Wageningen T 0317483953

E info.livestockresearch@wur.nl www.wur.nl/ livestock-research
Wageningen Livestock Research ontwikkelt kennis voor een zorgvuldige en renderende veehouderij, vertaalt deze naar praktijkgerichte oplossingen en innovaties, en zorgt voor doorstroming van deze kennis. Onze wetenschappelijke kennis op het gebied van veehouderijsystemen en van voeding, genetica, welzijn en milieu-impact van landbouwhuisdieren integreren we, samen met onze klanten, tot veehouderijconcepten voor de 21 e eeuw.

De missie van Wageningen University \& Research is 'To explore the potential of nature to improve the quality of life'. Binnen Wageningen University \& Research bundelen 9 gespecialiseerde onderzoeksinstituten van Stichting Wageningen Research en Wageningen University hun krachten om bij te dragen aan de oplossing van belangrijke vragen in het domein van gezonde voeding en leefomgeving. Met ongeveer 30 vestigingen, 6.500 medewerkers en 10.000 studenten behoort Wageningen University \& Research wereldwijd tot de aansprekende kennisinstellingen binnen haar domein. De integrale benadering van de vraagstukken en de samenwerking tussen verschillende disciplines vormen het hart van de unieke Wageningen aanpak. 